\title{
Juego de Tronos: La tragedia de un Estado que debe funcionar entre los eventuales excesos de un Presidente con competencias reforzadas y las reacciones desproporcionadas de un Congreso incontrolable - y el rol que un Tribunal Constitucional puede cumplir al respecto-
}

\section{Eloy Espinosa-Saldaña Barrera}

Doctor con mención sobresaliente Summa Cum Laude y Premio Extraordinario de la Universidad Nacional de Educación a Distancia de España. Catedrático de Derecho Constitucional y Derecho Administrativo. Magistrado y ex Vicepresidente del Tribunal Constitucional del Perú.

SUMARIO:

I. Una explicación inicial.

II. La materia aquí a enfrentar: las imprecisiones de nuestro sistema de gobierno y la determinación de qué puede entenderse como constitucionalmente posible en ese escenario.

III. EI Derecho Constitucional y las relaciones entre los "poderes" Ejecutivo Gobierno-y Legislativo - Congreso-.

IV. Sistema de gobierno y principio de separación de poderes en la Constitución de 1993.

V. La cuestión de confianza de septiembre de 2019 y la discusión que generó en el Perú.

1. ¿El Poder Ejecutivo peruano podía hacer cuestión de confianza sobre respecto a la elección de magistrados del Tribunal Constitucional, interrumpiendo el proceso ya iniciado? ¿Sobre qué puede hacerse cuestión de confianza y sobre qué no?

2. ¿Pueden haber denegatorias de confianza "fácticas" 0 "implícitas"?

3. ¿El Ejecutivo estaba facultado para disolver el Congreso de acuerdo con lo estipulado en el artículo 134 de la Constitución?

VI. Cuando una causal de vacancia erróneamente interpretada se convierte en una manera rápida de desprenderse de un/a Presidente/a incómodo/a para una mayoría parlamentaria: una historia reciente que ojalá no se repita.

VII. A modo de conclusión: las tareas y funciones de un Tribunal Constitucional y sus alcances ante la existencia de lo constitucionalmente posible y lo constitucionalmente obligatorio. 


\section{RESUMEN:}

El Perú ha atravesado una serie de crisis constitucionales en los últimos años, que han puesto de relieve la importancia de la labor del Tribunal Constitucional en la política peruana. El autor, Magistrado del órgano constitucional, reflexiona sobre dos casos en particular: la disolución del Congreso de la República del 30 de septiembre de 2019 y la vacancia presidencial del 09 de noviembre de 2020, sus implicancias constitucionales y la validez de los actos a la luz de la Carta Magna, además de analizar las posturas que ha tomado el Tribunal en los últimos años acerca de las facultades que tiene el Ejecutivo para plantear cuestiones de confianza y en general la estructura constitucional del Estado en lo relativo a la separación de poderes.

Palabras clave: Tribunal Constitucional, cuestión de confianza, disolución del Congreso, vacancia presidencial, constitucionalmente posible, incapacidad moral, separación de poderes, balance de poderes.

\footnotetext{
ABSTRACT:

Peru has undergone a series of constitutional crisis in the last years which have brought to the attention of society the paramount importance of the Peruvian Constitutional Tribunal in Peruvian politics. The author, Justice of the Constitutional Tribunal, analyses two particular cases: the dissolution of Congress of 30 September 2019 and the impeachment trial of 9 November 2020, their constitutional implications and the validity of those actions inside the framework established by the Constitution; furthermore analysing the positions the Tribunal has adopted in the last years on the abilities of the Executive to propose motions of no confidence and in general the constitutional structure of the State relative to the separation of powers.

Keywords: Constitutional Tribunal of Peru, motion of no confidence, dissolution of Congress, impeachment, constitutionally possible, moral incapacity, separation of powers, balance of powers.
}

\section{UNA EXPLICACIÓN INICIAL}

El 9 de noviembre de 2020, tras la culminación de un amplio debate con la exposición de los puntos de vista de los voceros y miembros de las distintas bancadas del Congreso, votaron a favor del pedido de destitución del entonces Presidente Martín Vizcarra 105 legisladores, 19 lo hicieron en contra y hubo cuatro abstenciones. Se recurrió para ello al distorsionado uso de una causal de vacancia, la de "grave y permanente incapacidad moral", en base a que aspirantes a colaboradores eficaces revelaran que Martín Vizcarra habría recibido sobornos cuando se desempeñó como Gobernador Regional de Moquegua -2011-2014- por los proyectos de la irrigación "Lomas de llo" y del Hospital de Moquegua.

No era la primera vez que se intentaba vacar a Vizcarra. Poco tiempo antes, un grupo de congresistas había pedido vacarlo, recurriendo a la misma causal, en función a unos contratos bastante discutibles en favor de Richard Cisneros, quien usaba el nombre artístico de "Richard Swing", persona cuya vinculación con el entor- no de Palacio de Gobierno intentó desbaratarse en forma insostenible. La moción de vacancia presentada por estas razones no alcanzó la cantidad de votos suficientes.

Estos graves incidentes se dan con alguien quien llega a la Presidencia de la República Vizcarra-, quien luego fue inicialmente sometido a una moción de vacancia por la conocida "grave y permanente incapacidad moral"; y quien, ante la imposibilidad de evitar ser vacado en una segunda ocasión, decidió renunciar antes de exponerse a esa situación. Frente a lo sucedido, Vizcarra pronto entra en su situación de enfrentamiento con la mayoría de congresistas, a pesar de no tener bancada parlamentaria propia. Este escenario de conflicto tuvo un momento destacado cuando el 30 de septiembre de 2019, Vizcarra resuelve la disolución del Congreso entonces en funciones, decisión que muchos defendieron y otros consideraron como inconstitucional.

Lo cierto es que la situación política es extremadamente preocupante. En una semana nuestro país contó con tres presidentes: Martín Vizcarra, 
para muchos derrocado por una interrupción del Estado Constitucional; Manuel Merino de Lama - presidente del Congreso cuya acción algunos consideraron como "golpista" y quien, ante el rechazo popular a su sostenimiento como Presidente, recurrió a una excesiva e injustificable represión de la protesta prácticamente rechazada por toda la población, por lo que tuvo que renunciar a la Presidencia de la República-; y el Presidente actual, Francisco Sagasti, que asume tal responsabilidad luego de su nombramiento como como Presidente del Congreso encargado de la Presidencia mientras se procede a elecciones presidenciales y parlamentarias en abril del año 2021, y se haga un total recambio de autoridades el 28 de julio de 2021.

Al respecto, y a pesar de que se había interpuesto una demanda competencial destinada a qué debe entenderse por "grave y permanente incapacidad moral", cuatro magistrados - entre los cuales, por cierto, no nos encontramos- desconocieron el verdadero sentido de un proceso competencial, y eludieron un pronunciamiento sobre el contenido y alcances de lo solicitado, amparando una declaración de improcedencia en base de una supuesta sustracción de materia. Esto es, por decirlo menos, una elusión a sus funciones de pacificar, integrar y ordenar.

Todo el cuadro aquí descrito, demuestra que aquí hay mar de fondo, el cual se hace necesario entender.

$Y$ es que a pesar de ser un Estado con un sistema de gobierno presidencial, en el Perú, como en muchos países latinoamericanos, se ha buscado atenuar el poder del Presidente de la República - formal y materialmente mayor que el del Presidente de los Estados Unidos de América-, incorporando a su Constitución y a sus leyes instrumentos de control propios de un sistema parlamentario fuera de su contexto original.

Aquello, lejos de resolver algunas inevitables diferencias entre Gobierno y Congreso, ha aumentado dichas tensiones, generando situaciones de verdadera crisis política, como las gene- radas en los ya mencionados 9 de noviembre de 2020 y 30 de septiembre de 2019.

El 9 de noviembre, la vacancia de Vizcarra generó un rechazo popular, mas no en defensa del presidente para muchos inconstitucionalmente vacado: en contra de la actuación de la clase política. Anteriormente, y en relación a lo ocurrido el 30 de setiembre, cuatro de siete miembros del Tribunal Constitucional decidieron que la decisión tomada por el Presidente del Perú era constitucional, decisión que iba en las antípodas de lo inicialmente hecho por el Congreso. La disolución no fue acatada por los congresistas, quienes buscaron suspender en sus funciones al Presidente Vizcarra y nombraron a una encargada de la Presidencia, quien renunció a ese encargo al día siguiente. Fue entonces al Tribunal Constitucional peruano quien, a través de un proceso competencial, dio una salida jurídica definitiva al respecto.

Todo esto es lo que explicaremos en la primera parte del presente trabajo, tarea que iniciaremos de inmediato, haciendo algunas reflexiones que esperamos resulten de alguna utilidad.

\section{LA MATERIA AQUÍ A ENFRENTAR: LAS IMPRECISIONES DE NUESTRO SISTEMA DE GOBIERNO Y LA DETERMINACIÓN DE QUÉ PUEDE ENTENDERSE COMO CONS- TITUCIONALMENTE POSIBLE EN ESE ES- CENARIO}

Cuando hablamos de sistema de gobierno, nos referimos a la categoría jurídica mediante la cual se establece, dentro de una configuración orgánica del poder, a sus límites y su justificación, y a la organización del Estado - la cual en el Estado Constitucional se identifica con la tutela de un conjunto de principios, derechos y valores-.

El Perú, desde su fundación, y por razones que ya no corresponde detallar aquí, optó por un modelo presidencial, con un Presidente que es a la vez jefe de Estado y jefe de Gobierno y, por ende, que puede contar con mucho poder, máxime si alguno de los limites existentes tradicionalmente reconocidos en los Estados Uni-

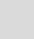


dos no le son exigidos al Presidente peruano. En el Perú cabe veto parcial de leyes, iniciativa legislativa presidencial con carácter preferente, capacidad legislativa propia - decretos legislativos y decretos de urgencia- $y$, por no ser muy exhaustivos, tiene competencias impensables para un presidente de los Estados Unidos, pues en estas actividades el margen del control del Congreso estadounidense es mucho más amplio - dictado de Estados de Excepción, un mayor manejo del impulso de transferencias presupuestales, y un gran etcétera-.

De otro lado, en cualquier Estado del mundo la complejidad de las relaciones entre un Gobierno y un Parlamento o Congreso - según en qué tradición jurídica nos encontremos- siempre es grande. Aun cuando se haya optado por un sistema presidencial "puro" o uno parlamentario "puro", siempre habrá tensiones sobre hasta dónde llega la competencia de uno y dónde termina la del otro, y en qué contexto y condiciones caben competencias compartidas. Ahora bien, la materia se hace aún más compleja cuando, dentro del llamado "presidencialismo latinoamericano", se ha optado desde muy pronto por introducir en un contexto básicamente presidencial elementos propios de una dinámica propia del parlamentarismo. Aquello genera una serie de problemas donde, dentro de lo "constitucionalmente posible" -que no necesariamente es lo más técnico o lo que más agrada-, hay que buscar respuestas nuevas, o reformular las alternativas "viejas" a lo que se presenta y, peor aún, a lo que se puede presentar.

\section{EL DERECHO CONSTITUCIONAL Y LAS RELACIONES ENTRE LOS “PODERES” EJE- CUTIVO - GOBIERNO- Y LEGISLATIVO -CONGRESO-}

En cualquier caso, resulta evidente que las relaciones entre los poderes Ejecutivo y el Legislativo, y sin duda también las posibles tensiones entre ambos poderes, pueden manifestarse de distinto modo dentro de un Estado, y pueden expresarse incluso de maneras que no han sido previstas o reguladas expresamente por la Constitución. Como es evidente, estas situaciones no podrían manejarse únicamente con base en reglas o procedimientos jurídicamente preestablecidos y detallados; sino que, en varias situaciones, y muy a despecho de lo incluído dentro del amplio marco de la interpretación constitucional - y en ella, lo "constitucionalmente posible"-, dichas relaciones o tensiones habitualmente quedan, en un primer momento y en buena medida, condicionadas por la negociación o coordinación política que puedan realizar los propios actores involucrados.

En cualquier caso, y tal como el Tribunal Constitucional peruano ha expresado en más de una ocasión, no debe perderse de vista que toda Constitución democrática establece un conjunto de mandatos de prohibición y otros de obligación. Así, delimitan lo que el Estado y las personas pueden hacer o dejar de hacer. La Carta fundamental peruana establece asuntos que deben realizarse necesariamente, así como otros que proscribe en definitiva. Es pues en ese escenario, y circunscrito por tales exigencias que cabe hablar de lo "constitucionalmente posible" o "permitido":

"Las diferentes disposiciones constitucionales pueden prever un contenido normativo 'constitucionalmente necesario' (lo que está ordenado por la Constitución y no se puede dejar de hacer, respetar o acatar), 'constitucionalmente imposible' (lo que está prohibido por la Constitución y no se puede hacer de ningún modo), o 'constitucionalmente posible' (lo que está delegado por la Constitución por ejemplo al legislador porque no está ordenado ni está prohibido)." 1

Al respecto, y en atención a los casos que le ha tocado resolver al Tribunal Constitucional peruano, estos se han referido, por lo general, a los límites y el margen de acción con que cuenta el Congreso de la República al ejercer sus com-

1. Sentencia del Tribunal Constitucional —en adelante, "STC" - recaída en el Expediente N00013-2010-PI, fundamento jurídico 2. 
petencias legislativas. No obstante ello, mutatis mutandis, lo mismo puede decirse respecto a los demás poderes públicos y sus propias competencias, como bien puede desprenderse de lo que consignaré a continuación:

"En este esquema metodológico, puede establecerse que el control de la acción positiva del legislador está en directa relación con lo que es 'constitucionalmente imposible'. Cuando la actividad del legislador a través de la ley incursiona dentro de este ámbito, la actuación del Tribunal se orienta a eliminar dicha intromisión prohibida por la Constitución. En cambio el control de las omisiones al legislador se ubicaría en lo que es 'constitucionalmente necesario' y no obstante no ha sido atendido por el legislador. Finalmente aquello que es 'solo constitucionalmente posible' se ubica en terreno propio del legislador y por tanto puede ser atendido en la forma en que lo crea conveniente e incluso en el tiempo que lo juzgue necesario. De este modo, la acción del Tribunal Constitucional se legitima, tanto para el control de lo que está constitucionalmente prohibido, así como para exigir aquello que resulta 'constitucionalmente ne-

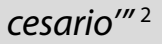

"El rol del legislador u otra autoridad estatal en el desarrollo normativo de la Constitución no es una mera labor de órgano ejecutor de los mandatos dispuestos por la Norma Fundamental; le cabe pues al órgano normativo un margen amplio de configuración de las disposiciones constitucionales, con los límites que la Constitución impone, e incluso una cierta discrecionalidad en el momento en el cual realizar la labor de desarrollo normativo; sin embargo, este Tribunal también asume que dicho desarrollo discrecional de la competencia normativa no puede suponer tampoco una absoluta libertad normativa, pues ello sería tanto como dejar los propios derechos fundamentales en manos del le- gislador, sobre todo cuando estos derechos requieren para su plena vigencia del desarrollo normativo llevado a cabo por este o cuando requieren su actuación normativa para frenar situaciones de grave y manifiesta inconstitucionalidad"3 ${ }^{\prime 3}$ el subrayado es nuestro-.

En este mismo sentido, puede afirmarse que las competencias de los poderes públicos $-\mathrm{y}$ la forma en que éstos se relacionan - tienen un amplio margen de acción para poder desplegarse, siempre y cuando éstas se encuentren dentro de lo constitucionalmente posible. En dicho orden de ideas, un Tribunal Constitucional no es quien dictamina todo aquello que pueden hacer o no los poderes públicos dentro del libre margen de acción constitucional. Su rol consiste, más bien, en controlar que tales poderes no se excedan en sus funciones, sin transgredir aquello que les viene constitucionalmente impuesto como obligatorio o prohibido; y que asegure lo que puede asumirse como constitucionalmente posible.

Conforme a lo indicado, queda claro que, a pesar del mencionado margen de acción amplio con el que cuentan los poderes públicos, incluso en situaciones de crispación o enfrentamiento, dichos poderes no pueden exceder los límites y salvaguardas previamente establecidas - o por lo menos esbozadas - por la Constitución y las leyes de desarrollo constitucional. De esta manera, la política debe desenvolverse dentro de los cauces que, por ejemplo, brinda el sistema de partidos políticos, el método previsto para la asignación de escaños en las elecciones parlamentarias, la regulación existente en torno a la organización de los partidos políticos y a los grupos parlamentarios, las competencias y funciones de los poderes del Estado, entre otros factores. En similar sentido, existen asimismo otras instituciones más directamente referidas a la relación entre Gobierno y Congreso, como las que en el caso peruano aparecen

2. STC recaída en el Expediente $\mathrm{N}^{\circ}$ 00006-2008-PI, fundamento jurídico 39.

3. STC recaída en el Expediente Nº 05427-2009-PC, fundamento jurídico 17. 
reguladas expresamente en el Título IV, Capítulo VI, de la Constitución del Perú —artículos 130 al 136 - las cuales circunscriben y limitan nuestro sistema de gobierno.

Sobre esto último, la historia y la experiencia vivida en el Perú han requerido que nuestro sistema de gobierno se vaya ajustando paulatinamente, lo que ha servido para delinear su particular identidad que, sin perjuicio de lo que indicaremos luego, es la de un régimen presidencial al cual se le han introducido instituciones inicialmente generadas en regímenes parlamentarios. $Y$ es que ha sido precisamente con base en lo que algunos denominan nuestra "Constitución histórica" que ha venido apareciendo en nuestras normas fundamentales más recientes un marcado énfasis en el establecimiento de frenos y cortapisas entre los tradicionalmente denominados "poderes del Estado". En dicho marco han terminado acogiéndose instituciones de orígenes diversos, los cuales incluso pueden considerarse como funcional y conceptualmente antagónicas entre sí.

Al respecto, el hecho de que se haya asumido una forma de gobierno basado en controles recíprocos, pesos y contrapesos, implica, desde luego, aceptar que existen tensiones y discrepancias políticas que son inherentes al sistema democrático. Estas tensiones, no cabe duda, pueden ser más o menos agudas, más o menos duraderas; pero, en todo caso, se encuentran latentes en la dinámica política y -en el marco de un Estado Constitucional como el nuestrodeben necesariamente ser canalizadas a través de los mecanismos constitucionales existentes. En este sentido, la Constitución, repito, no debe entenderse como una especie de "camisa de fuerza" que aprisione y ahogue las relaciones políticas, pero tampoco como un mero papel mojado en tinta, carente de eficacia jurídica real para encauzar y limitar a los poderes. Así visto, los poderes políticos pueden actuar con libertad, pero dentro del "orden" o "marco constitucional": es decir, circunscribiendo su accionar a lo constitucionalmente posible o permitido, cuyos contornos infranqueables están constituidos por lo constitucionalmente prohibido y lo constitucionalmente obligatorio o exigible.

Señalado esto, ya que las relaciones y tensiones entre los poderes políticos se encuentran jurídicamente acotadas dentro de un orden marco infranqueable, es absurdo - a la vez que inconstitucional- despotricar contra la juridificación y la judicialización de la política. Más aún, debe tenerse en cuenta que uno de los principales y más elevados propósitos de la Constitución -y, más ampliamente, del mismo Estado Constitucional- es subordinar al poder político, atajando cualquier posible forma de arbitrariedad $y$, en ese sentido, el de garantizar que el quehacer político respete caracteres constitucionales y convencionales, por lo que cabe señalar lo siguiente:

"[A]firmar que existen actos de alguna entidad estatal cuya validez constitucional no puede ser objeto de control constitucional, supone sostener, con el mismo énfasis, que en tales ámbitos la Constitución ha perdido su condición de norma jurídica, para volver a ser una mera carta política referencial, incapaz de vincular al poder (...)

\section{(...) La judicialización de la Constitución o, para ser más exactos, la de todo acto que a ella contravenga, es la máxima garantía de que su exigibilidad (...) no está sujeta a los pareceres de intereses particulares; por el contrario, todo interés individual o colectivo, para ser constitucionalmente válido, debe manifestarse de conformidad con cada una de las reglas y principios, formales y sustanti- vos, previstos en la Carta Fundamental." 4}

Anotado lo anterior, no es difícil entender que (i) pueden existir situaciones de tensión entre los poderes frente a las cuales la Constitución no ha previsto un desarrollo respecto a los procedimientos que deben seguirse; y que, asimismo, (ii) de primera impresión puede no ser

4. STC recaída en el Expediente $\mathrm{N}^{\circ}$ 05854-2005-PA, fundamentos jurídicos 7 y 8. 
claro el significado de ciertas expresiones que usa la Norma Fundamental, las cuales podrían resultar aplicables a la solución de, por ejemplo, un conflicto político.

Al respecto, en primer lugar, debe indicarse que es normal y hasta deseable que las relaciones políticas no queden circunscritas a unas pocas habilitaciones detalladas expresamente: por el contrario, parece más bien necesario que éstas se desenvuelvan dentro de ámbitos de discrecionalidad y deliberación política, que tal vez podrían verse asfixiados por exceso de reglamentación. De esta forma, si bien es necesaria la constitucionalización y la juridización de la política, quizá pueda considerarse como contraproducente su hiperjuridización.

En segundo lugar, en cuanto a la apertura interpretativa de la Constitución, relacionada a la ambigüedad o vaguedad de algunas de sus cláusulas, a esa amplitud de sentidos normativos con que cuentan las disposiciones constitucionales, justo es anotar que esta característica de los términos constitucionales puede terminar desencadenando una verdadera "disputa interpretativa" a nivel de la sociedad y los especialistas. Aquello, que es propio de todas las democracias pluralistas, no solo tiene relación con aquellos argumentos "técnico-jurídicos" que ofrecen quienes intervienen en el intercambio de puntos de vista, sino que tienen relación, asimismo, con los casos política o moralmente más controvertidos, con las opiniones o preferencias políticas e ideológicas de cada quien.

Frente a ello, precisamente le corresponde a un Tribunal Constitucional, en su condición de órgano de cierre de la interpretación vigente y vinculante de la Constitución, resolver ese tipo de controversias, brindando respuestas que tiendan a la racionalización del conflicto político y a la superación posturas antagónicas, máxime si, prima facie, estas aparecen como irreductibles entre sí, debido sobre todo a las diferencias políticas o ideológicas que están detrás de ellas.

La respuesta que podría brindar el Tribunal Constitucional en un caso como este, entonces, no puede tener como objetivo poner fin a la discusión política entre los actores políticos involucrados. Lo que podía pretender, legítimamente, atendiendo a sus funciones de mediación, integración social y orientación que le son propias a los tribunales constitucionales, así como a la luz del rol moderador y pacificador de las controversias sociales que las cortes constitucionales cumplen, es esclarecer que, en controversias como esta, se pone especialmente de manifiesto el carácter no solo normativo-regulatorio, sino también político-institucional de la Constitución. Ese carácter particular de la Norma Fundamental implica, en ocasiones, que puede existir una insuficiente o deficiente regulación constitucional pues la realidad política excede con creces lo que puede ser regulado-. Ello exige a la judicatura constitucional no solo completar los vacíos o las imprecisiones jurídico-constitucionales que pudieran detectarse en la Constitución - por ejemplo, las llamadas lagunas normativas, lagunas de conocimiento o las lagunas axiológicas inclusive- a través del uso de técnicas jurídicas, sino que dicha integración debe realizarse teniendo como base los principios que subyacen a nuestro sistema de gobierno y a nuestro sistema político; y apostando, al propio tiempo, por fórmulas de respuesta que aseguren la integración social.

Es precisamente con miras a cumplir lograr este rol de integración social y de pacificación de las controversias que este órgano colegiado, todo tribunal constitucional en general y el peruano en particular, debe resolver una controversia constitucional de esta clase, sin dejar de explicitar, ciertamente, los márgenes constitucionales que deben respetar en todo caso los poderes públicos en conflicto. No solamente entonces se limita a resolver un caso, sino pasa a fijar criterios que, en términos de interpretación, van a ser de especial utilidad para atender si posteriormente se presentan casos con elementos similares.

\section{SISTEMA DE GOBIERNO Y PRINCIPIO DE SEPARACIÓN DE PODERES EN LA CONS- TITUCIÓN DE 1993}

A efectos de analizar y resolver adecuadamente el fondo la presente controversia es

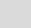


necesario establecer, cuando menos de manera general, cuál es el sistema de gobierno que ha adoptado el Perú, así como alcances del principio de separación de poderes en ese contexto, máxime si nos estamos refiriendo a aspectos con reconocimiento o desarrollo en nuestra propia Constitución. Esto último tiene vital relevancia, debido a que únicamente en dicho marco es que pueden entenderse a cabalidad los contornos constitucionales de las relaciones existentes entre los llamados poderes del Estado -e incluso entre éstos con los órganos constitucionales autónomos-, y más específicamente, qué debe comprenderse por las relaciones entre los diferentes Gobiernos y los Congresos.

Respecto a lo indicado, lo primero que corresponde señalar es que esta no es la primera oportunidad en la que el Tribunal Constitucional peruano se refiere a este tema. Por el contrario, y precisamente atendiendo a su función moderadora del poder y pacificadora de conflictos, este órgano colegiado ha tenido la oportunidad de pronunciarse y de esclarecer algunas cuestiones referidas a este tema con anterioridad. Así, ha señalado, por ejemplo y en primer lugar, el valor de la separación de poderes dentro del marco del constitucionalismo contemporáneo. Efectivamente, este Tribunal Constitucional ha recordado que la separación de poderes es una técnica que tiene como finalidad evitar la concentración del poder $-y$ a la vez, añadiríamos nosotros, organizarlo y justificarlo- $y$, en tal sentido, se encuentra encaminada a garantizar que los "poderes" y órganos constitucionalmente autónomos del Estado puedan ejercer sus competencias o atribuciones. Asimismo, busca evitar cualquier trasgresión de los derechos fundamentales de las personas que derive de un eventual ejercicio abusivo o incontrolado del poder político:

"La existencia de este sistema de equilibrio y de distribución de poderes, con todos los matices y correcciones que impone la socie- dad actual, sigue constituyendo, en su idea central, una exigencia ineludible en todo Estado Democrático y Social de Derecho. La separación de estas tres funciones básicas de Estado, limitándose de modo recíproco, sin entorpecerse innecesariamente, constituye una garantía para los derechos constitucionalmente reconocidos e, idénticamente, para limitar el poder frente al absolutismo y la dictadura. ${ }^{15}$

Por otra parte, se ha señalado que la separación de poderes no debe entenderse hoy en día - a diferencia de lo que tal vez se concibió en algún momento- como una división tajante entre las funciones del Estado, sin puntos de contacto o interrelación entre los denominados poderes del Estado y los distintos organismos constitucionalmente autónomos. Debe ser más bien considerada en clave de equilibrio entre órganos, de controles recíprocos, de frenos y contrapesos. Pero no solo ello: también con base en relaciones de lealtad, coordinación y de cooperación entre esas entidades:

"La separación de poderes que configura nuestra Constitución no es absoluta, porque de la estructura y funciones de los Poderes del Estado regulados por la Norma Suprema, también se desprende el principio de colaboración de poderes. Al respecto, encontramos una colaboración de poderes cuando el artículo 104 de la Constitución establece que el Congreso puede delegar en el Poder Ejecutivo la facultad de legislar, mediante decretos legislativos, sobre materia específica y por el plazo determinado establecidos en la ley autoritativa. Del mismo modo, existe una colaboración de poderes cuando el artículo 129 de la Constitución dispone que el Consejo de Ministros en pleno, o los ministros por separado, pueden concurrir a las sesiones del Congreso y participar en sus debates con las mismas prerrogativas que los parlamentarios, salvo la de votar si no son congresistas.

5. STC recaída en el Expediente $\mathrm{N}^{\circ}$ 0023-2003-Al, fundamento jurídico 5. 
Ocurre lo mismo con las normas constitucionales relativas al proceso de elaboración de la Ley de Presupuesto." ${ }^{6}$

"Uno de esos principios constitucionales que el Poder Judicial debe respetar, como todo Poder del Estado y todo órgano constitucional, es el de separación del poder, reconocido en el artículo 43 de la Constitución. Este principio no debe ser entendido en su concepción clásica, esto es, en el sentido que establece una separación tajante y sin relaciones entre los distintos poderes del Estado; por el contrario, exige que se le conciba, por un lado, como control y balance entre los poderes del Estado - checks and balances of powers-y, por otro, como coordinación y cooperación entre ellos. Esto explica el hecho de que si bien la Constitución establece que ninguna autoridad puede avocarse a causas pendientes ante el órgano jurisdiccional ni interferir en el ejercicio de sus funciones (artículo $138^{\circ}$ inciso 2), dimana de ella también la prescripción de que el Poder Judicial no ha de turbar, ilegítimamente, el ejercicio de las atribuciones de otros poderes del Estado." ${ }^{7}$

Finalmente, el Tribunal Constitucional peruano ha precisado asimismo que la distribución de poderes, o de funciones desde una perspectiva más amplia, no se reduce a tomar en cuenta tan solo a los tres "poderes del Estado", sino que debe considerarse asimismo el papel que repetimos, juegan los organismos constitucionalmente autónomos en dicha configuración de funciones constitucionalmente relevantes para el contrapeso y el control del poder:

"El principio de separación de poderes reconocido en el artículo 43 de la Constitución posee un contenido más amplio que aquel que asumía la separación del poder del Estado únicamente en poderes como el legisla- tivo, ejecutivo y judicial. En efecto, la propia Norma Fundamental ha establecido órganos constitucionales tales como el Tribunal Constitucional (artículo 201 y ss.), Jurado Nacional de Elecciones (176 y ss.), Ministerio Público (artículo 158 y ss.), Consejo Nacional de la Magistratura (artículo 150 y ss.), Defensoría del Pueblo (artículo 161 y ss.), Gobiernos locales y Gobiernos regionales (artículo 190 y ss.), entre otros.

Como se aprecia, el Poder Constituyente ha divido el poder no solo entre el Poder Legislativo, Poder Ejecutivo y Poder Judicial, sino también entre órganos constitucionales, sin desconocer, inclusive, que también es posible explicar la moderna materialización del principio de separación de poderes con la división entre órganos de decisión política (parlamento y gobierno) y los órganos de decisión jurisdiccional (judicatura ordinaria y constitucional, entre otros). Pese a la extensión del número de instituciones que administran el poder, se mantiene el núcleo esencial del principio, el mismo que consiste en evitar la concentración del poder en un solo ente." 8

Formulado este marco, es necesario hacer algunas precisiones sobre el sistema de gobierno que viene regulado actualmente en nuestro texto constitucional. Al respecto, y como habitualmente se señala, existen dos modelos "clásicos" de forma de gobierno formulados idealmente, que son el modelo "parlamentario" y otro "presidencial". En el caso del régimen presidencial, este se caracteriza básicamente porque hay un Jefe de Gobierno, denominado por lo general Presidente. Este proviene de una elección popular, hace simultáneamente las veces de Jefe de Estado, y no es nombrado ni -en principio- removido discrecionalmente por el Congreso. En el caso del régimen parla-

6. STC recaída en el Expediente $\mathrm{N}^{\circ}$ 00004-2004-CC, fundamento jurídico 24.

7. STC recaída en el Expediente $\mathrm{N}^{\circ}$ 00006-2006-CC, fundamento jurídico 15.

8. STC recaída en el Expediente $\mathrm{N}^{\circ}$ 00005-2007-Al, fundamento jurídico 21. 
mentario, por el contrario, tenemos que el Jefe de Gobierno es elegido por el Parlamento, que lo puede remover discrecionalmente $y$, además, por lo general la jefatura del Estado recae en un órgano distinto al Jefe de Gobierno -el cual puede ser un monarca constitucional o un Presidente, por ejemplo-.

En el caso peruano, como en prácticamente toda América Latina, partimos de un modelo inicialmente presidencial, en la medida que nuestro Jefe de Gobierno se denomina Presidente de la República, es electo popularmente, cumple las funciones de Jefe de Estado y no es nombrado ni removido discrecionalmente por el Congreso de la República. Sin embargo, progresivamente nuestras constituciones han incorporado al modelo algunas instituciones del parlamentarismo, las cuales dejan de lado una tradicionalmente más estricta división de poderes que distingue al modelo ideal presidencial. En el Perú tenemos, entonces, que el Gobierno requiere de aprobación política del Congreso para la conformación de parte del mismo - el gabinete-, así como para su eventual cambio. Entre estas instituciones de origen parlamentario incorporadas en el caso peruano tenemos al voto de confianza, la censura ministerial y las cuestiones de confianza, por solamente mencionar algunas.

En efecto, al regular nuestro sistema de gobierno, la Constitución peruana, como muchas otras latinoamericanas, ha recogido diferentes instituciones que, en perspectiva, permiten distinguirla de los modelos ideales o clásicos presidencial y parlamentarista. Frente a ello, la doctrina se ha referido a nuestro régimen o forma de gobierno de diferentes modos. Por ejemplo, hay quienes le han llamado régimen "semipresidencial", en el sentido de que no es uno en estricto presidencial, pues se incorpora, como ya fue indicado, mecanismos de control y límites propios del régimen parlamentarista. También se ha considerado que nuestro régimen puede calificarse asimismo como "hiperpresidencialista", en atención a los descomedidos poderes con los que, aparentemente, contaría el Presidente, en especial cuando tiene mayoría oficialista en el Congreso, y también en atención a nuestras experiencias de caudillismo y autoritarismo.

En similar sentido, y atendiendo a las particulares y a veces abultadas atribuciones establecidas a favor de los presidentes en nuestra región, se ha hablado asimismo de un "presidencialismo latinoamericano"; el cual, como señala reconocida doctrina, viene siendo replanteado a través de la inclusión de elementos de balance y contrapeso propios del parlamentarismo, en un modelo que cabría calificar como "semiparlamentarismo". En esa línea, hubo quienes tomando en cuenta nuestra base presidencial, pero también las incorporaciones traídas del parlamentarismo, hablaban de un régimen "semiparlamentario". También se ha hecho uso de los calificativos "mixto" o "híbrido", o incluso "presidencialismo parlamentarizado". Todo lo expuesto permite dar cuenta de la dificultad para encasillar nuestra forma de gobierno en alguno de los modelos clásicos, pero eludiendo finalmente definirla o calificarla en atención a sus propios contornos y especificidades.

Ahora bien, el modelo de gobierno nace de la propia Constitución del Perú y, por ende, únicamente puede ser con base en dicho parámetro constitucional que puede intentar comprenderse a cabalidad los contenidos y alcances de nuestro régimen de gobierno en la presente sentencia. En el igual sentido, los poderes públicos, al momento de ejercer sus funciones y competencias, solo pueden actuar conforme a lo que nuestra norma Fundamental ha establecido. En este orden de ideas, cualquier distorsión o trasgresión del modelo de gobierno adoptado constitucionalmente, a través de actos normativos -mediante la dación de normas, básicamente legales- o de actos materiales - mediante trasgresiones de hecho-, deberá reputarse como inconstitucional.

Llegados a este punto, no debemos olvidar que la separación de poderes es un rasgo identitario no solo de la Constitución peruana, sino del constitucionalismo en general. En dicho sentido, el Tribunal Constitucional peruano ha 
recordado ${ }^{9}$ por ejemplo cómo, en la emblemática obra El espíritu de las Leyes, Montesquieu sostuvo que:

"No hay libertad si el poder de juzgar no está bien deslindado del poder legislativo y del poder ejecutivo. Si no está separado del poder legislativo, se podría disponer arbitrariamente de la libertad y vida de los ciudadanos; como que el juez sería el legislador. Si no está separado del poder ejecutivo, el juez podría tener la fuerza de un opresor. Todo se habría perdido si el mismo hombre, la misma corporación de próceres, la misma asamblea del pueblo ejerciera los tres poderes. El de dictar las leyes; el de ejecutar las resoluciones judiciales y el de juzgar los delitos o pleitos entre particulares."

En este mismo sentido, a la separación de poderes se le ha entendido desde el siglo XVIII como un contenido mínimo imprescindible que hace reconocible al constitucionalismo, tal como en su momento fue dispuesto por el artículo 16 de la Declaración de los Derechos del Hombre y del Ciudadano del año 1789:

"Toda sociedad en la cual no esté establecida la garantía de los derechos, ni determinada la separación de los poderes, carece de Constitución."

Precisamente, y con base a este rasgo de identidad de nuestro constitucionalismo, el Tribunal Constitucional peruano ha expresado, de manera categórica, que lo concerniente a la "separación de poderes" — como parte de nuestro sistema de gobierno- constituye un límite para, por ejemplo, la reforma ordinaria de la Constitución, pues forma parte de una especie de "núcleo duro", que comprende a los "principios y presupuestos básicos de la organización política, económica y social" contenidos en nuestra carta Fundamental. Por ende, dicho ámbito no puede ser objeto de una reforma constitucional apelando únicamente a las competencias de reforma con las que cuen- ta el Congreso - un poder constituido-, sino que dicho cambio más bien sería expresión de una "reforma total" de la Constitución, la cual requiere de la anuencia del poder constituyente soberano, por ejemplo, a través de un referéndum:

"Aunque toda Constitución se caracteriza por ser un cuerpo normativo integral, donde cada disposición cumple un determinado rol, ciertas cláusulas asumen una función que resulta mucho más vital u omnicomprensiva que las del resto. Se trata de aquellos valores materiales y principios fundamentales que dan identidad o que constituyen la esencia del texto constitucional (la primacía de la persona, la dignidad, la vida, la igualdad, el Estado de Derecho, la separación de poderes, etc.). Sin ellos, la Constitución sería un texto formalmente supremo pero, en cambio, materialmente vacío de sentido."

"Los límites materiales [a la reforma constitucional], están constituidos por aquellos principios supremos del ordenamiento constitucional que no pueden ser tocados por la obra del poder reformador de la Constitución (...) [Los límites materiales implícitos, son aqueIlos principios supremos de la Constitución contenidos en la fórmula política del Estado y que no pueden ser modificados, aun cuando la Constitución no diga nada sobre la posibilidad o no de su reforma, ya que una modificación que los alcance sencillamente implicaría la "destrucción" de la Constitución. Tales son los casos de los principios referidos a la dignidad del hombre, soberanía del pueblo, Estado democrático de derecho, forma republicana de gobierno y, en general, régimen político y forma de Estado."

\section{(...)}

"La elaboración del proyecto de la nueva Constitución [o la "reforma total"] en sede parlamentaria, necesaria e inexorablemente deba concluir con su sometimiento a referén-

9. STC recaída en el Expediente $\mathrm{N}^{\circ}$ 00023-2003-Al, fundamento jurídico 4. 
dum, so pena de declararse la inconstitucionalidad de dicho proceso. Es preciso, pues, que de continuarse como se está haciendo el proceso de cambio de Constitución, la aprobación de la nueva Norma Fundamental tenga que realizarse a través del referéndum, la única forma como puede expresarse directamente el Poder Constituyente. $Y$ es que cuando mediante referéndum se aprueba sólo una reforma parcial de la Constitución, en tal caso la intervención del pueblo se presenta como un elemento que incide exclusivamente sobre la eficacia. Lo que no sucede, por cierto, cuando el pueblo actúa en calidad de Poder Constituyente, en cuyo caso la aprobación de la Constitución la realiza él mismo y su decisión es un elemento constitutivo de su elaboración." 10

Señalado todo esto, y siendo clara entonces la importancia del sistema de gobierno constitucionalmente establecido en el Perú y sus particularidades, resulta necesario que su Tribunal Constitucional precise o desarrolle una descripción o definición, cuando menos general, sobre algunos de sus contornos, siempre a partir de lo constitucionalmente previsto.

Al respecto, una primera cuestión podría encontrarse relacionada con la nomenclatura que mejor permitiría calificar o denominar a nuestro régimen de gobierno. Si bien es cierto que el nombre no es lo más importante a efectos de reconocer los contornos del modelo, atribuir uno, sin duda, ayuda a reconocer sus rasgos de identidad, sus alcances, potencialidades y límites. En este sentido, el Tribunal Constitucional del Perú ha precisado similares calificaciones, siempre precisando sus alances, al referirse, por ejemplo, a nuestra forma de Estado - Estado unitario y descentralizado-, a nuestro régimen político-económico - Economía social de mercado-, a las relaciones entre Estado y religión - Estado laico-, a nuestro actual estadio de constitucionalismo -Estado Constitucional-, entre varios otros supuestos.
Ahora bien, e independientemente de lo que acabo de anotar, es importante expresar cómo en el Perú, en primer lugar, las relaciones entre el Gobierno y el Congreso, tanto atendiendo a lo que dice la Constitución, como a la concreción de sus instituciones en la práctica reciente, pueden ser de distinto tipo y con diferentes efectos, siendo incluso hasta diametralmente opuestos entre sí en algunos contextos.

Efectivamente, en el marco de lo constitucionalmente previsto, hay dos escenarios o supuestos extremos, en los cuales nuestro modelo se manifiesta de modo muy diferente. En el primer escenario lo tenemos cuando un gobierno cuenta una mayoría parlamentaria absoluta escenario de "oficialismo robusto"-; mientras que también existe el escenario opuesto, el del gobierno con una oposición parlamentaria arrolladora - supuesto que podemos denominar de "oposición robusta"-. Cuando estamos ante un gobierno que cuenta con un "oficialismo robusto", como puede preverse, al ponerse en riesgo la separación de poderes debido a un eventual fortalecimiento excesivo e incontrolable del gobierno de turno, los mecanismos que permiten el control político por parte de las minorías parlamentarias adquieren una relevancia especial, como es el caso, por ejemplo, de la interpelación ministerial, la moción de censura. De otro lado, el uso de las demandas de inconstitucionalidad toma también un rol importante.

En el segundo caso, de "oposición robusta", si se quiere trabajar dentro de parámetros democráticos, adquieren relevancia más bien los mecanismos de diálogo y coordinación, de contrapeso político o, finalmente, de solución de controversias políticas en contextos de crisis de gobernabilidad o institucional. En este contexto de gobierno con "oposición robusta", y de enfrentamiento entre poderes o crisis institucional, pueden presentarse dos supuestos que cabe considerar extremos. De una parte, el del impulso de la vacancia del Presidente de la República, generalmente por "incapacidad mo- 
ral"; y por otra, el del eventual cierre del Congreso de la República como consecuencia de que se hayan producido dos crisis totales del gabinete por denegatoria de confianza o por censura al Presidente del Consejo de Ministros.

Visto así, no es posible calificar a nuestro sistema de gobierno únicamente poniendo énfasis en uno de los escenarios: es decir, ni solo atendiendo a la posible concentración del poder en manos del Ejecutivo en escenarios de "oficialismo robusto", ni necesariamente en una actitud obstruccionista, que hace imposible la gobernabilidad, en el marco de Ejecutivos que se enfrentan a una "oposición robusta" al interior del Congreso. Más aun, es necesario considerar que, además de los supuestos extremos ya esbozados, puede existir entre ellos escenarios variopintos, tales como gobiernos con una primera mayoría parlamentaria, gobiernos con una segunda mayoría congresal, gobiernos con mayoría parlamentaria a través de alianzas con otras agrupaciones - cogobierno-, gobiernos con minoría parlamentaria y gobernabilidad a través de acuerdos coyunturales, gobiernos con minoría congresal y sin gobernabilidad por dispersión política — no existen coincidencias políticas o programáticas entre las diferentes agrupaciones políticas-, etc.

Con base en lo señalado, es posible constatar en el sistema de gobierno peruano - y de buena parte de América Latina - una suerte de "Presidencialismo Asimétrico" o "Intermitente", en atención a que las instituciones, e incluso el propio régimen de gobierno, no operan siempre del mismo modo o con la misma intensidad. Por ende, en diferentes contextos, algunas instituciones, sus alcances y límites adquieren diferente entidad; $y$ por ende, plantean cuestiones y problemas de carácter constitucional que correspondería enfrentar teniendo en cuenta el contexto indicado.

Señalado esto, es claro que una descripción o delimitación de este tipo de modelos en manos de la judicatura constitucional debe ser tomada con especial cuidado, evitando o previniendo los excesos, las desviaciones y la desnaturalización del régimen. En otras palabras, buscando actuar siempre dentro de los términos constitucionalmente dispuestos. Al respecto, y como ya ha sido señalado, un Tribunal Constitucional a estos efectos debe hacer uso de su rol de "poder moderador", conforme al cual trata de evitar o apaciguar los posibles conflictos que puedan dañar la institucionalidad del país, aunque desde luego sin invadir competencias que le sean ajenas.

En este orden de ideas, es posible intentar definir los contornos de nuestro régimen de gobierno peruano, coincidentemente con buena parte de América Latina, sobre la base de los siguientes elementos:

a) Principio de separación de poderes: Hace referencia a la autonomía funcional y a las diferentes competencias que cada poder estatal $-y$ también cada órgano constitucional autónomo - tiene, pero también a las distintas funciones - sociales, políticas - que cada uno cumple tendencialmente - tales como representar, legislar y fiscalizar en el caso del Congreso, o de gobernar y hacer cumplir las leyes en el caso del Gobierno-. Este principio, desde luego, conlleva a reconocer las eventuales tensiones que puedan surgir entre los poderes políticos.

Con base al principio de separación de poderes es claro que nuestro modelo presidencialista latinoamericano no aspira entonces, a diferencia de lo que ocurre en un régimen parlamentarista, a la confusión o subordinación entre los poderes, o a la asunción de que existe algo así como un "primer poder" de Estado. Se reconoce, pues, la división de poderes, y se prevén formas razonables para resolver o superar las diferencias entre ellos.

b) Principio de balance entre poderes: Alude a la existencia de mecanismos de coordinación - tales como la delegación de facultades, el respaldo a políticas de gobierno a través de la cuestión confianza, las coordinaciones o negociaciones políticas para la aprobación del presupuesto público, la

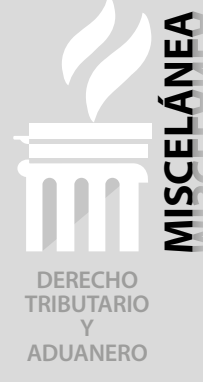


reglamentación de las leyes, la iniciativa legislativa por parte del Poder Ejecutivo o los órganos constitucionales autónomos, etc. -; de control recíproco - control jurídico y jurídico-político entre los poderes y órganos constitucionales autónomos-; y de equilibrio entre poderes - respeto a la autonomía de los otros poderes y órganos constitucionales autónomos, regulación de competencias y funciones ajenas sin desnaturalizarlas, debida asignación presupuestaria para los poderes estatales $u$ órganos constitucionales autónomos, etc.- -

Además de que no hay aquí poderes subordinados, a lo cual sí se refería el principio anterior, el principio de balance entre poderes permite destacar que en el modelo constitucional peruano, por no decir, latinoamericano, los poderes estatales, como también los órganos constitucionalmente autónomos, se conciben en una dinámica de balance o contrapeso, lo cual exige reconocer y respetar los mecanismos de equilibrio y control constitucionalmente previstos.

Como corolario de lo anterior, se tiene que la regulación, el ejercicio e incluso la interpretación de los alcances de los mecanismos de coordinación, de control recíproco o de equilibrio entre poderes no pueden realizarse alterando o desnaturalizando el balance que ha buscado asegurar la Constitución, lo cual es parte medular de nuestro modelo.

c) Principio de cooperación: Conforme a este principio, la interpretación de las competencias y las funciones de los poderes y órganos constitucionales autónomos deben estar orientadas al cumplimiento de los fines del Estado -artículo 44 de la Constitución-, o a la concreción del conjunto de bienes y valores constitucionales - pudiéndose mencionar, a modo de ejemplo, lo señalado en los artículos 3, 38, 43 o 45 de la Constitución-, y siempre teniendo como horizonte la defensa de la persona humana y el respeto a su dignidad —artículo 1 de la Constitución-.
De esta manera, entre los poderes públicos y los organismos u órganos constitucionales autónomos resulta de aplicación el principio de "lealtad constitucional", lealtad que, además del respeto a las competencias y funciones ajenas, orienta el comportamiento de los actores estatales hacia la consecución del bien común, que debe ser el fin último de la política.

Así visto, con base en este principio de cooperación deben evitarse conductas obstruccionistas, desleales o egoístas por parte de los poderes o actores políticos. Al respecto, si bien la política tiene una faz agonal inevitable —es decir, relativa a la confrontación o lucha entre actores-, las instituciones y competencias constitucionales deben ser interpretadas y ejercidas en el sentido de fomentar la integración social, la unidad política, y la optimización de los fines y principios constitucionales, entre otros. Lo anterior, desde luego, resulta especialmente relevante en el caso del análisis que le corresponde realizar a un Tribunal Constitucional en los casos sometidos ante él, atendiendo a su rol moderador y pacificador de conflictos.

d) Principio de solución democrática: Este principio pone de relieve que frente a un entrampamiento o crisis política o institucional que no puede superarse a través de los medios institucionales habituales, debe preferirse, en primer lugar, las salidas deliberativas - es decir, mediante el diálogo institucional, o a través de los espacios de deliberación pertinentes y adecuados para enfrentar los conflictos políticos- $y$, únicamente en su defecto, apelar a la elección popular como ratio final y superior.

De esta manera, este sistema de gobierno, así como las relaciones entre los poderes públicos, debe tender a establecer y preferir mecanismos de dialogo que permitan resolver las controversias sin apelar, en primer término, a formas plebiscitarias o meramente mayoritarias de democracia. En ese sentido, corresponde a los actores 
políticos e institucionales, y desde luego en ello juega también un rol central un Tribunal Constitucional, promover que en las instancias de discusión institucional se produzcan diálogos robustos e inclusivos, lo cual comprende, desde luego, la necesidad de incorporar a los ciudadanos, en especial a los directamente afectados por un medida, y a los especialistas, en el proceso de toma de decisiones, y solo si dicho diálogo fracasa, y se produce una crisis política o institucional irresoluble, será posible y hasta necesario apelar al depositario originario del poder político: los ciudadanos, el pueblo.

Al tratarse todos estos de principios que identifican a la forma de gobierno peruana, y en buena medida latinoamericana, y que permiten delimitar debidamente las relaciones entre los denominados poderes del Estado - y las de ellos con los organismos constitucionalmente autónomos-, su regulación y ejercicio deben estar entonces encaminados siempre al respeto de las mencionadas señas de identidad previstas en la Constitución, sin desnaturalizarlas ni vaciarlas de contenido. Son parte, pues, del ya referido "núcleo duro" de una Norma Fundamental, en los términos ya recordados en este texto.

Asimismo, es necesario insistir en que los poderes públicos y los organismos constitucionalmente autónomos deben operar siempre bajo el ya enunciado principio de lealtad constitucional, el cual ha tenido una indudable importancia al delimitar las relaciones entre los niveles de gobierno en otras latitudes, y al cual el Tribunal Constitucional del Perú también se ha referido en diversas ocasiones - por ejemplo, al hacer referencia a la reforma constitucional, en la STC recaída en el Expediente $\mathrm{N}^{\circ} 00050$ 2004-Pl; a nuestra forma de Estado y a la relación entre los gobiernos nacional y regional, en la STC recaída en el Expediente $N^{\circ}$ 00034-2009$\mathrm{Al}$; o a la forma de gobierno y la relación entre los poderes públicos, en la STC recaída en el Expediente $\mathrm{N}^{\circ}$ 00006-2018-Al-.

La lealtad constitucional, ciertamente, no implica únicamente tener en cuenta las compe- tencias que hayan sido formal o literalmente establecidas a cada quien; sino que el ejercicio de tales competencias, así como el comportamiento de los actores involucrados en dicho ejercicio, debe ser respetuoso de los principios de identidad de nuestro régimen de gobierno antes enunciados. Esto con el propósito de poder alcanzar, como comunidad política, el bien común en el marco de un modelo de Estado constitucional.

\section{LA CUESTIÓN DE CONFIANZA DE SEP- TIEMBRE DE 2019 Y LA DISCUSIÓN QUE GENERÓ EN EL PERÚ}

El Tribunal Constitucional peruano ya ha tenido ocasión de pronunciarse de manera específica sobre la cuestión de confianza. Más concretamente, este Tribunal declaró la inconstitucionalidad de la Resolución Legislativa N ${ }^{\circ} 007$ 2017-2018-CR, norma que buscó modificar al Reglamento del Congreso de la República. Allí se había regulado que el Presidente del Consejo de Ministros no podía hacer cuestión de confianza respecto de la aprobación de leyes ni de procedimientos de control político.

En dicha oportunidad el Tribunal Constitucional señaló que la cuestión de confianza fue introducida en el constitucionalismo peruano como un mecanismo destinado a realizar labores de contrapeso de los gobiernos de turno, con la finalidad de hacerle frente a la censura ministerial que el Congreso tiene en sus manos, por lo que debe ser entendida con base en el ya mencionado principio de balance entre poderes. En aquella oportunidad este órgano colegiado indicó, asimismo, que conforme a la Constitución, se presentan dos situaciones distintas en las cuales aparece la figura de la cuestión de confianza: la llamada cuestión de confianza obligatoria, que consiste en la solicitud por parte del Gobierno al Congreso de la República, cuando se conforma un nuevo gabinete, de un voto de confianza - y no de investidura- para que el Congreso legitime la conformación del Consejo de Ministros — artículo 130 de la Constitución-. Esta debe diferenciarse de la cuestión de confianza facultativa, que es aquella que puede plantear ante el Congreso, 
tanto el Presidente del Consejo de Ministros a nombre del Consejo, como a cada ministro de manera individual, para así pedir anuencia o respaldo político respecto de algún asunto que considere pertinente plantear -artículos 132 y 133 de la Constitución-.

Asimismo, en tal ocasión el Tribunal Constitucional peruano precisó que

"(...) la cuestión de confianza que pueden plantear los ministros ha sido regulada en la Constitución de manera abierta, con la clara finalidad de brindar al Poder Ejecutivo un amplio campo de posibilidades en busca de respaldo político por parte del Congreso, para llevar a cabo las políticas que su gestión requiere." 11

Se sostuvo, además, que resulta contrario al principio de balance entre poderes el restringir, indebidamente, la facultad que tienen los ministros para poder plantear al Congreso cuestiones de confianza respecto de los asuntos que la gestión del Ejecutivo requiera, por lo cual es posible solicitar cuestiones de confianza orientadas, por ejemplo, a la aprobación de normas legales o para interrumpir procedimientos legislativos o de control político.

En el presente caso, vinculado a los sucesos del 30 de septiembre de 2019, los demandantes cuestionan que el Gobierno peruano haya formulado cuestión de confianza respecto al proceso de elección de magistrados del Tribunal Constitucional. Se solicitó al Congreso de la República que discuta prioritariamente un proyecto de reforma del procedimiento de elección y que, a tales efectos, suspenda la elección de magistrados que se encontraba en marcha. Con base en este proceder inicial, que no implicaba un retiro de la titularidad constitucionalmente otorgada al Congreso de elegir a magistrados y magistradas del Tribunal Constitucional, sino la revisión de un trámite procedimental $-\mathrm{y}$, por ende, de aplicación inmediata- que buscaba hacer más transparente el procedimiento, ya cuestionado por entidades internacionales, el quehacer del Gobierno generó diversas consecuencias que también son cuestionadas en esta causa -entre ellas, principalmente, el cierre del Congreso-, las cuales luego analizaremos.

Al respecto, y conforme a lo explicado ampliamente en la STC recaída en el Expediente $\mathrm{N}^{\circ}$ 0006-2018-PI, es claro que el Gobierno podía hacer cuestión de confianza respecto a proyectos de ley, como finalmente lo hizo el Presidente del Consejo de Ministros ante el Congreso de la República, en la sesión del Pleno del 30 de septiembre de 2019. Además de ello, no debe olvidarse la misma práctica parlamentaria reciente -el Congreso había concedido cuestiones de confianza incluso para plantear reformas constitucionales sometidas a referéndum-. Finalmente, y si bien dentro de un escenario más discutible, cierto es que, como parte de lo ocurrido el 30 de septiembre de 2019, el Congreso finalmente, y con las precisiones que se harán luego, otorga "formalmente" la cuestión de confianza solicitada.

Además, y contrariamente a lo que sostuvieron los demandantes, el Gobierno no planteó su pedido en términos impositivos, sino a modo de una propuesta que debía discutirse en el seno del Congreso, la cual por cierto era respetuosa de la competencia constitucionalmente asignada al Congreso en relación con la elección de magistrados y magistradas del Tribunal Constitucional. En este orden de ideas, y a mayor abundamiento, se encuentra que el proyecto de ley no contenía alcances que pudieran considerarse como invasivos de las competencias del Congreso, pues tan solo establece estándares relacionados con el procedimiento de elección de jueces o juezas del Tribunal Constitucional, con base en los usos internacionales y las prácticas previas relacionadas con la elección de magistrados constitucionales -en buena medida, los utilizados cuando se nos designó juez constitucional-.

11. STC recaída en el Expediente $\mathrm{N}^{\circ}$ 0006-2018-PI, fundamento jurídico 75. 
Sin embargo, y estando claro que era posible plantear cuestión de confianza respecto de iniciativas legislativas, existen aún algunas cuestiones que merecen ser esclarecidas por este órgano constitucional, y que han sido objeto de diversos debates en la opinión pública y entre quienes se reclaman especialistas en la materia, las cuales pueden reconducirse, en lo esencial, a los siguientes tres asuntos:

1. ¿El Poder Ejecutivo podía hacer cuestión de confianza sobre la elección de magistrados del Tribunal Constitucional, interrumpiendo el proceso ya iniciado? En similar sentido, y de manera más genérica: ¿sobre qué puede hacerse cuestión de confianza y sobre qué no?;

2. ¿Puede haber denegatorias de confianza "fácticas" o "implícitas"?; y por último, con base en lo anterior,

3. ¿El Ejecutivo estaba facultado para disolver el Congreso, como ocurrió el 30 de septiembre de 2019, de acuerdo con lo estipulado en el artículo 134 de la Constitución?

En lo que sigue procederemos a desarrollar tales cuestiones, una por una.

1. ¿El Poder Ejecutivo peruano podía hacer cuestión de confianza sobre respecto a la elección de magistrados del Tribunal Constitucional, interrumpiendo el proceso ya iniciado? ¿Sobre qué puede hacerse cuestión de confianza y sobre qué no?

Estas primeras interrogantes nos plantean la duda respecto a sobre qué materias, finalmente, es posible hacer cuestión de confianza, y si cabe plantar cuestiones de confianza sobre, por ejemplo, asuntos tales como la interrupción del procedimiento de elección de magistrados de un Tribunal Constitucional. Al respecto, es claro que la llamada cuestión de confianza obligatoria - es decir, aquella que debe solicitarse obligatoriamente tras la conformación de un nuevo gabinete- debe plantearse básicamente respecto de políticas de gobierno; en tal sentido, en este supuesto hay algunas materias sobre las cuales es claro que puede - y debe- plantearse cuestión de confianza ante el Congreso. Por otra parte, como ya fue reseñado, si estamos ante un supuesto diferente, en relación con la cuestión de confianza facultativa -es decir, aquella confianza planteada por los ministros, o por quien preside el Gabinete, respecto de un asunto específico- que se encuentra regulada de manera abierta y, por ende, puede tratar sobre diversos temas.

Con base a esta apertura inicial, vale la pena distinguir entre las materias y los actos parlamentarios que pueden ser objeto de un pedido de cuestión de confianza, abordando los problemas relacionados con cada uno de estos supuestos. Con respecto a los actos parlamentarios que pueden ser objeto de un pedido de cuestión de confianza, como ya fue recordado, en la STC recaída en el Expediente $\mathrm{N}^{\circ}$ 000062018-PI, el Tribunal Constitucional peruano declaró inconstitucional la Resolución Legislativa $N^{\circ}$ 007-2017- 2018/CR, en el extremo que indicaba que "[n]o procede la interposición de una cuestión de confianza cuando esté destinada a promover, interrumpir o impedir la aprobación de una norma o un procedimiento legislativo o de control político." En este orden de ideas, quedó claro que el mecanismo de la cuestión de confianza puede ser utilizado para "promover, interrumpir o impedir" la aprobación de normas legales, la tramitación de procedimientos legislativos - parlamentarios-y de procedimientos de control político. Entonces, y de manera general, se puede colegir que puede plantearse cuestiones de confianza con la finalidad de "promover, interrumpir o impedir" el ejercicio de competencias propias del Congreso de la República, materializadas a través de diversos los procedimientos parlamentarios.

Al respecto, es claro que un tipo de procedimiento parlamentario es el procedimiento de elección o ratificación de altos funcionarios por parte del Congreso - Ilamado "procedimiento especial" por el Reglamento del Congreso-, procedimiento de elección política que se perfecciona con la publicación de las concernientes resoluciones legislativas en el Diario Oficial. . 
En suma, conforme a lo resuelto ya en la STC recaída en el Expediente $\mathrm{N}^{\circ}$ 00006-2018-PI, es constitucionalmente posible que el Gobierno formule cuestiones de confianza con el objeto de "interrumpir" o "impedir" diversos procedimientos parlamentarios, entre ellos el de elección de altas autoridades, como es el caso de los magistrados o magistradas del Tribunal Constitucional. Ello, máxime, repetimos, si los procedimientos de variación de un trámite en curso - sobre todo, si se busca mayor transparencia - son de aplicación inmediata.

Ahora bien, y en lo referido a los actos legislativos pasibles de cuestión de confianza, debe precisarse entonces, a mayor abundamiento, que es absurdo cuestionar que el Gobierno plantee cuestiones de confianza respecto de actos o asuntos que son de competencia exclusiva o excluyente del Congreso de la República. Ello es así, porque la cuestión de confianza precisamente está diseñada para que el Gobierno, en el contexto de nuestro sistema de gobierno, pueda poner a consideración del Congreso asuntos que este no puede o debe llevar a cabo en solitario, sino que estemos ante asuntos donde se requiere del concurso y acompañamiento de otro Poder del Estado, lo que sin duda va en la línea del ya mencionado principio de cooperación entre poderes. En similar sentido, es irrazonable sostener que el Gobierno solo puede plantear cuestiones de confianza respecto de cuestiones que forman parte de las competencias del propio Gobierno; pues, si ese fuera el caso, sería innecesario que el Gobierno formule pedido alguno al Congreso de la República, debido a que podría ejercer tales competencias por su cuenta, sin plantear alguna cuestión de confianza al referido poder público.

Ahora bien, y no obstante esta posibilidad de que las cuestiones de confianza puedan formularse respecto de muy diversos actos parlamentarios, debemos preguntarnos aún si existe alguna limitación en relación con los temas o las materias sobre las que puede presentarse una cuestión de confianza.

Al respecto, es claro que dicha facultad debe con- tar con algunos límites. Ello con la finalidad de evitar que, con su ejercicio, se produzcan eventuales abusos o incluso trasgresiones a nuestro modelo constitucional de régimen de gobierno. En este sentido, la cuestión de confianza debe entenderse, en principio, de manera amplia, pues se trata de un mecanismo de naturaleza política, con un gran margen de discrecionalidad para plantearse o no plantearse -en este sentido, también tienen esta naturaleza, por ejemplo, la censura ministerial o el nombramiento de ministros-. Por ende, no podría estar sujeto a un reglamentarismo excesivo que desnaturalice su función de contrapeso político, ni podría derivarse tampoco la permanente judicialización de su uso, salvo en situaciones excepcionales que, en principio, tendrían que determinarse por o con el concurso de un Tribunal Constitucional. De lo anterior, pues, no se deduce que se trate de un mecanismo carente de límites, pues ello sería contrario a los principios de separación de poderes, cooperación entre poderes y de solución democrática.

Ciertamente, el riesgo puede considerarse mayor aún si se toma en consideración los graves efectos que pueden generarse tras dos denegaciones de confianza al Presidente del Consejo de Ministros, suerte de ministro coordinador del Gabinete, mas no Jefe de Estado o Jefe de Gobierno, atribuciones que concentra el Presidente de la República peruano - y en buena medida, situación aplicable a toda América Latina-. Dicho escenario, en caso fuere mal utilizado, puede acarrear excesos al plantearse indebidamente cuestiones de confianza y, con ello, destruir el equilibrio de poderes que pretende asegurar nuestra Carta Fundamental.

En ese contexto, considero que, entre los límites más claros que puede tener la cuestión de confianza, puedo encontrar, entre otros:

a) La proscripción de cuestiones de confianza "ficticias" —o "en blanco"—, cuando estas, atendiendo a que se trata de una herramienta de contrapeso del Gobierno frente al Congreso, cuya finalidad está orientada al equilibrio entre poderes, se usen de manera desnaturalizada y constituyan esencialmente un fraude a la Constitución, 
mediante las cuales se busque forzar indebidamente su cierre, infringiendo así principios como los de balance y de separación de poderes.

No obstante lo indicado, debo precisar que, de todos modos, sí sería posible admitir, de manera excepcional, cuestiones de confianza planteadas con el único propósito de gatillar el procedimiento de disolución del Congreso. Tal situación de excepción podría darse, por ejemplo, en el caso en el de que exista consenso o acuerdo entre los diferentes actores políticos para acortar periodos de mandato, lo cual sería compatible con los principios de cooperación entre poderes y de solución democrática de controversias. Sin embargo, y conforme a lo indicado, tal posibilidad quedaría claramente proscrita cuando el uso de estas cuestiones de confianza encubra fines fraudulentos, protervos o puramente individuales, carentes de sustento constitucional. $^{12}$

b) La prohibición de cuestiones de confianza orientadas a la disminución o desaparición de derechos fundamentales. Al respecto, de acuerdo con el artículo 1 de la Constitución, "la defensa de la persona humana y el respeto de su dignidad son el fin supremo de la sociedad y del Estado", y conforme al artículo 44 es un deber fundamental del Estado "garantizar la plena vigencia de los derechos humanos". Desde esta perspectiva, debe considerarse como manifiestamente inconstitucional cualquier iniciativa que vaya en contra precisamente de este "fin supremo de la sociedad y del Estado", con lo cual se defraude un "deber primordial" del poder público. c) La proscripción de cuestiones de confianza manifiestamente inconstitucionales. Se trata aquí del caso en que la cuestión de confianza se realiza respecto de contenidos o medidas que resulten contrarias a la Constitución, además de los derechos fundamentales. Tal sería el caso, por ejemplo, si el Ejecutivo impulsara reformas constitucionales únicamente con doble votación del Congreso -artículo 206-, pero respecto de contenidos que forman parte del denominado "núcleo duro" de la Constitución, trasgrediendo de este modo los límites materiales de la reforma constitucional, como es el caso de nuestro modelo constitucional de forma de Estado, forma de gobierno, régimen republicano, sistema político democrático, etc. ${ }^{13}$, o si el Gobierno planteara que se lleve a referéndum cuestiones sobre las cuáles no se puede consultar - artículo 32-.

Señalado lo anterior, y volviendo a la cuestión de confianza que fue planteada el 30 de septiembre de 2019 y, más específicamente, en relación con la interrupción del procedimiento de elección de magistrados, debe tenerse en cuenta, además de lo ya indicado sobre los asuntos respecto a los cuales es posible formular cuestión de confianza, que la presentación de un proyecto de ley para mejorar el procedimiento de elección de magistrados del Tribunal Constitucional, promoviendo su transparencia y legitimación, se encuentra directamente relacionado con los ejes de gobierno - contenidos en los ejes de la "Política General de Gobierno al 2021", aprobada mediante Decreto Supremo $\mathrm{N}^{\circ}$ 056-2018-PCM-que, en su momento, justificaron que el Gobierno planteara la reforma constitucional relacionada con el ex Consejo Nacional de la Magistratura —este es el caso

12. El Tribunal Federal Constitucional Alemán se pronunció en un caso sobre la cuestión de confianza destinada solo al adelanto de elecciones señalando que esta era admisible siempre que estuviera orientada a lograr un gobierno viable. Cfr. Dilmar Villena, "¿Es viable constitucionalmente presentar una cuestión de confianza con la única intención de disolver el parlamento?" EnfoqueDerecho, 11 de septiembre de 2019, acceso el 20 de marzo de 2021, https://www.enfoquederecho.com/2019/06/11/es-viable-constitucionalmente-presentar-una-cuestion-de-confianza-con-la-unica-intencion-de-disolver-el-parlamento/. 
de las políticas de "lucha contra la corrupción" y de "fortalecimiento de la institucionalidad"-, práctica que en su momento fue aceptada por el Congreso de la República.

En este sentido, y con independencia de las alegaciones que se han formulado de que no podría hacerse cuestiones de confianza respecto de competencias exclusivas del Congreso - como es el caso de reformas legales o constitucionales- o que los temas vinculados a lo jurisdiccional no son cuestiones que le competan al Gobierno, lo cierto es que el Congreso de la República del Perú con anterioridad ya ha aceptado la tramitación y ha aprobado cuestiones de confianza con dicho tenor, precisamente en el marco de lo constitucionalmente posible, lo cual constituye un hito en la configuración de nuestra forma de gobierno y la construcción de nuestra Constitución histórica.

Con base en todo lo indicado, entonces, es claro que el Gobierno peruano podía plantear cuestión de confianza al Congreso de la República respecto del procedimiento de elección de magistrados del Tribunal Constitucional, y más específicamente respecto a su procedimiento de elección - procedimiento de elección política-, máxime si dicha elección se encuentra vinculada a ejes de gobierno - "lucha contra la corrupción" y de "fortalecimiento de la institucionalidad"- que, en su momento, justificaron para el propio Congreso la presentación, e incluso la aprobación, de otra cuestión de confianza.

Señalado todo lo anterior, y habiéndose confirmado que era posible plantear una cuestión de confianza como la que fue sustentada el 30 de septiembre de 2019 ante el Pleno del Congreso de la República, todavía queda por discutir si el Ejecutivo podía asumir o interpretar, como finalmente ocurrió, que la confianza fue denegada, no formalmente, sino debido al comportamiento del Congreso.

\section{2. ¿Pueden haber denegatorias de confian- za "fácticas" o "implícitas"?}

Inicialmente, es claro que en el Perú una cuestión de confianza facultativa —es decir, aquella planteada por propia iniciativa del Presidente del Consejo de Ministros o por cualquier ministro- debe ser programada y luego votada en el Pleno del Congreso. Ahora bien, la cuestión compleja se presenta cuando existen decisiones o procedimientos iniciados por el Congreso de la República y que el Gobierno considera que deban ser atendidos con premura o urgencia, en el marco del contrapeso entre poderes y nuestro diseño institucional. Al respecto, conforme al diseño constitucional peruano, el Congreso cuenta con diversas herramientas para limitar el accionar de un gobierno, o para responsabilizarlo políticamente con premura. Ello no ocurre igual en sentido contrario, cuando menos expresamente o conforme a las prácticas usuales.

Ahora bien, lo cierto es que, en el caso concreto, el Gobierno peruano primero pidió un trámite preferente del proyecto, al amparo del artículo 105 de la Constitución. Luego, a pesar de una injustificable resistencia, que bien pudo apreciarse incluso a través de los medios de comunicación, el Presidente del Consejo de Ministros hizo uso de la previsión constitucional -artículo 129-que permite expresa e indubitablemente a dicho Presidente del Consejo de Ministros, o a cualquier ministro, participar en toda sesión del Pleno del Congreso en los mismos términos que lo haría cualquier congresista salvo el derecho de votar, en caso el ministro no sea congresista-. Al tratarse de una prerrogativa constitucional a favor del Presidente del Consejo de Ministros - o de cualquiera de sus ministros/as inclusive - admitir su participación ante el Pleno no se trataba de una mera "cortesía" o una cuestión de protocolo, sino de una facultad constitucional que debe ejercerse sin cortapisas, en los mismos términos en que lo haría cualquier congresista, tal como prevé la Constitución.

Es precisamente en ejercicio de dicha prerrogativa que el Presidente del Consejo de Ministros planteó, el 30 de setiembre de 2019, una cuestión de confianza ante el Pleno del Congreso, "en ese mismo instante", "para que el Parlamento decida si nos otorga la confianza y considera por lo tanto que hay que hacer uso de transparencia 
[en el procedimiento de elección de magistrados del Tribunal Constitucional] o que nos la niegue, si considera que va a seguir adelante con ese procedimiento". Al respecto, es indubitable que el Presidente del Consejo de Ministros tenía el derecho de poder participar en esa o en cualquier otra sesión del Pleno del Congreso de la República. Asimismo, que dicho funcionario tenía la potestad de poder plantear una cuestión de confianza en relación con el procedimiento de elección de magistrados. Ambas son prerrogativas constitucionales que, en todo caso, debieron ser respetadas y facilitadas por el Congreso, y no, como finalmente ocurrió, obstaculizadas y hasta obviadas por parte del órgano parlamentario.

Al respecto, es necesario insistir en que los mecanismos de contrapeso, si bien han de resultar incómodos para los órganos que serán objeto de control o de enfrentamiento, ellos deben ser respetados y garantizados a pesar de cualquier malestar, pues de esto depende que perviva la institucionalidad contenida en la Constitución. Así, entonces, pese al fastidio o la irritación que puede generar que se utilicen los mecanismos políticos de extrema ratio como pueden ser los procedimientos de vacancia presidencial o de disolución del Congreso de la República, es necesario resguardar el correcto funcionamiento de tales instituciones, pues ello permite garantizar la separación y el balance entre poderes y; en última instancia, en caso de crisis profundas e irresolubles en las que haya fracasado cualquier mecanismo de coordinación o de diálogo, le otorga al soberano la decisión final a través de la cual puede producirse la recomposición del escenario político - esto opera frente a la disolución constitucional del Congreso, y en el caso de vacancias o renuncias presidenciales, cuando estas comprenden a todos los sucesores constitucionales-.

Volviendo a lo ocurrido el 30 de septiembre de 2019, tal como fue indicado, el Gobierno peruano, a través del Presidente del Consejo de Ministros, propuso al Congreso un cambio en el procedimiento de elección de magistrados. Al respecto, como se ha dicho aquí en varias ocasiones, las eventuales modificaciones de carácter procesal o procedimental deben ser apli- cadas de manera inmediata, incluso a los procedimientos en trámite, que es la indubitable regla a seguir frente a ese tipo de cambios. Siendo así, la cuestión de confianza que fue formulada por el Gobierno, y cuyo propósito era que se discutan las pautas procedimentales referidas a elección de magistrados del Tribunal Constitucional, en ese mismo momento, promoviendo una mayor transparencia del proceso, debería haberse atendido tomando en cuenta que los cambios eventualmente aprobados deberían aplicarse de manera inmediata. Dicho con otras palabras, incluso a la elección de magistrados en curso. En este orden de ideas, se desnaturalizaría el propósito de la cuestión de confianza si se postergaba su eventual aprobación -como finalmente ocurrió- hasta después de que se haya llevado a cabo las elecciones siguiendo las pautas y procedimientos que se planteaba modificar.

Señalado ello, y ante la evidencia de que no se tenía la intención de siquiera discutir lo planteado por el Gobierno, se constata que, luego de formulada la cuestión de confianza por el Presidente del Consejo de Ministros, el Congreso del Perú votó expresamente en contra de la "cuestión previa" que presentó una de sus congresistas, cuyo propósito era precisamente que se discuta, antes de la elección de magistrados del Tribunal Constitucional, la cuestión de confianza que acababa de presentarse. Era una salida saludable, pero lamentablemente desaprovechada. Asimismo, y de manera contraria a la cuestión de confianza que fue sustentada ante el Pleno, el Congreso de la República prosiguió con la elección de magistrados, llevando finalmente a votación dos candidaturas — una de las cuáles tuvo una serie de impugnaciones no resueltas y la otra no alcanzó los votos requeridos-. No había intención de discutir, y menos de acoger, la cuestión de confianza planteada.

Horas después de todo ello, es decir, tras haberse desestimado la cuestión previa, la cual planteaba que se discuta y vote primero la cuestión de confianza, antes de la elección programada para la fecha, y tras haberse continuado con el procedimiento de elección de magistrados, que el Presidente del Consejo de Ministros pidió

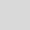


que se detenga, el Congreso recién discutió formalmente la cuestión de confianza, votándose a favor de otorgarla, ya cuando la intención que la motivaba había sido rehusada o rechazada. En ese marco, debe esclarecerse entonces si la confianza fue finalmente debe considerarse como denegada u otorgada.

En cualquier caso, debemos indicar que no es contraria a la Constitución una interpretación - o, en sentido estricto, una "calificación jurídica"- que considere que la votación formal a favor de una cuestión de confianza, pero que ha sido desestimada en los hechos, sea considerada como una denegación. Volvemos entonces al ámbito de lo constitucionalmente posible, y allí nos preguntamos si la denegatoria a una cuestión de confianza - mejor dicho, a una segunda cuestión de confianza-, debe ser expresa, o si, dentro de lo constitucionalmente posible, puede, haciéndose el seguimiento de una situación concreta como la aquí descrita, entenderse que está en el margen de lo "constitucionalmente posible" entender que en este caso se ha denegado o rehusado la segunda cuestión de confianza planteada - en esta ocasión, a un gabinete del gobierno del presidente Vizcarra, quien completa el periodo del presidente Kuczynski, el cual renunció al cargo presidencial一.

¿Puede hablarse de cuestión de confianza denegada cuando indefinidamente no se atiende el tema planteado o cuando se actúa en sentido contrario a lo solicitado, aun si posteriormente, de manera formal, se concede lo solicitado? ¿No son estos últimos supuestos también escenarios de denegatoria o rechazo de la confianza solicitada?

Por cierto, una interpretación sobre "rehusar" o "denegar" la confianza puede entenderse como análoga a la interpretación que viene haciendo el Tribunal Constitucional respecto a la expresión "resoluciones denegatorias", la cual aparece en el artículo 202, inciso 2 de la Constitución, referido a la procedencia del recurso de agravio constitucional. Al respecto, y como es por todos/as conocido, la Norma Fundamental regula que el recurso de agravio constitucional única- mente procede frente a resoluciones consideradas "denegatorias" $y$, a modo de desarrollo, el artículo 18 del Código Procesal Constitucional indica que tendrían tal condición aquellas "que declaran infundada o improcedente la demanda". No obstante ello, el Tribunal Constitucional peruano, a lo largo del tiempo - y con diferentes composiciones de magistrados - ha llegado a interpretar que puede considerarse como una "denegatoria" a aquella resolución que, pese a declarar fundada la demanda de manera formal o expresa, finalmente "deniega" justicia por ser materialmente contraria a la Constitución.

En este sentido último ya nos hemos expresado inclusive la mayoría de magistrados que hoy integramos el Tribunal Constitucional del Perú. Esto ocurrió en la STC recaída en el Expediente $\mathrm{N}^{\circ}$ 05811-2015-PHC, fundamento jurídico 7, donde indicamos que:

"No debe descartar ab initio que una sentencia estimatoria de segundo grado pueda ser lesiva de otros bienes constitucionales. Su calidad de estimatoria no implica necesariamente que sea conforme a la Constitución. Su verificación está por tanto abierta al control por parte del Tribunal Constitucional a través del recurso de agravio constitucional; más aún, cuando se trata de preservar el orden constitucional. De acuerdo con la jurisprudencia de este Tribunal, dicho recurso procede también, inclusive cuando se trate de sentencias estimatorias de segundo grado, de manera excepcional, en los siguientes casos: a) tráfico ilícito de drogas, b) lavado de activos, c) terrorismo."

Desde luego, debe señalarse, además, que el Tribunal Constitucional peruano, en diversos casos, ha procedido a interpretar el texto de normas legales de conformidad con la Constitución $-y$ con los diversos sentidos que puede dar una interpretación constitucional-, yendo más allá de lo literalmente dispuesto. Hay decenas de casos en lo que esto ha sucedido. Ello, más específicamente, ha ocurrido, por ejemplo, en el caso Ley de Servicio Civil 1, STC recaída en el Expediente $\mathrm{N}^{\circ}$ 00025-2013-PI y otros acumulados, en el cual 
se interpretó la constitucionalidad de la ley tan solo si se entiende como incorporada una expresión inexistente - "condiciones de trabajo o condiciones de empleo"- - Asimismo, está el caso Dicapi, STC recaída en el Expediente $\mathrm{N}^{\circ}$ 00001-2014-PI, en el que el Tribunal Constitucional peruano estableció límites para la actividad supervisora de la Dirección General de Capitanías y Guardacostas que no aparecían en la ley, enfatizando el carácter vinculante de lo resuelto por el mismo Tribunal desde una lectura directa del parámetro constitucional y los diferentes sentidos que razonablemente pueden entenderse de él.

Señalado esto, es necesario indicar que circunscribirse en estos casos a una interpretación de carácter meramente legalista -o "paleopositivista", en términos de Ferrajoli14_ podría incluso admitir un fraude a la Constitución, el cual consiste en la manipulación de una institución que, si bien es utilizada formalmente, su real propósito es perseguir un objetivo distante de su finalidad. Al respecto, debe señalarse con firmeza que el fraude a la Constitución, y en general toda forma de "ilícitos atípicos"15, se encuentran proscritos, con claridad, por el artículo 103 de la Constitución, a través de la prohibición expresa del abuso del Derecho, cuando allí se señala que: "La Constitución no ampara el abuso del derecho."

Asimismo, es necesario indicar que una interpretación en sentido contrario, puramente legalista -o "paleopositivista", repetimos, en los términos de Luigi Ferrajoli-, también implicaría admitir un grave riesgo de fraude a la Constitución. Dicho en otros términos, podría avalar la manipulación de una regulación, convalidando con ello una supuesta aprobación formal de la cuestión de confianza, mientras que en los hechos el Congreso peruano en realidad le está denegando, de manera clara, lo solicitado. Si hay rasgos claros, inobjetables de no cumplir - o de ni siquiera atender- lo que era la intención de una cuestión de confianza, cabe entonces dentro de lo constitucionalmente posible, y buscando evitar un fraude a la Constitución, asumir que nuevamente se ha denegado una cuestión de confianza y que, con ello, se configura un supuesto para la disolución del Congreso.

Ahora bien, y entendiendo que un Congreso de la República puede manifestar su voluntad de otorgar o rehusar confianza a través de manera no expresa, es necesario explicitar algunos recaudos para que ello no se haga de manera irresponsable o abusiva, de tal modo que Gobiernos como el peruano se consideren habilitados para interpretar cualquier acto del Congreso como una denegación de la confianza solicitada. A efectos de delimitar y limitar esta posibilidad, es necesario definir entonces de qué estamos hablando y en qué supuestos ésta es admisible. Respecto a esta situación de denegatoria no expresa, puede entenderse que se produce cuando median actos concluyentes, que pueden expresarse como hechos u omisiones deliberadas, los cuales de manera cierta -y no dudosa o solo probable-, además de objetiva - no meramente subjetiva - e inobjetable, otorgan certeza sobre la voluntad denegatoria del Congreso respecto de los asuntos planteados por el Gobierno, en el marco de un pedido de confianza.

Por otra parte, y en relación con los supuestos en los que puede considerarse que estamos ante actos concluyentes que pueden constituir una denegatoria no expresa de cuestiones de confianza planteadas, puedo enumerar de manera meramente enunciativa, y no exhaustiva, a los siguientes:

14. Cfr. Luigi Ferrajoli, "El Constitucionalismo garantista. Entre paleo-iuspositivismo y neo-iusnaturalismo", Doxa: Cuadernos de Filosofía del Derecho 34, (2011): 311-361.

15. Que para Manuel Atienza y Juan Ruiz Manero comprende el fraude a la ley, el abuso del derecho y la desviación de poder. Cfr. Manuel Atienza y Juan Ruiz Manero, llícitos atípicos. Sobre el abuso del derecho, el fraude de ley y la desviación de poder, (Madrid: Trotta, 2000). 
a) El rechazo continuo a discutir la cuestión de confianza planteada. Esto puede darse tanto por la negativa permanente a empezar la tramitación del pedido de cuestión de confianza, por posponer sine die la presentación que le correspondería hacer el ministro solicitante ante el Pleno del Congreso, por diferir ad infinitum la votación correspondiente, por no discutirse y votarse en el Pleno la cuestión antes de que el pedido formulado se desnaturalice o se torne inútil, etc.

b) El rechazo, en los hechos, de la cuestión de confianza, pese a su posterior aprobación formal. En este supuesto, se producen actos concluyentes que dan cuenta acerca de la voluntad del Congreso de denegar la confianza solicitada, de una forma tal que la posterior discusión o incluso la aprobación formal de la cuestión planteada sería manifiestamente inconducente, pues la cuestión que había sido planteada por el Gobierno ya no podría cumplir con su objetivo - el estado de cosas que se pretendía obtener-o finalidad - los principios o valores que se buscaba defender o promover-.

c) La aprobación formal de la cuestión de confianza planteada, pero el rechazo, en los hechos, de lo solicitado. De este modo, cabe considerar como actos concluyentes que equivalen a una denegación de confianza si, pese a que el Congreso apruebe lo solicitado a través de una votación, jamás llega a concretizarse lo acordado o si, al pretenderse avanzar en ello, finalmente se desnaturaliza o desvirtúa lo planteado por el Gobierno.

Ahora bien, de lo anterior no se desprende que un Gobierno pueda formular cuestiones de confianza que tengan como finalidad obligar al Congreso a decidir en un determinado sentido cuando dicho Congreso ejerce sus competencias exclusivas: es decir, buscando forzar el sentido de alguna decisión sobre las cuales le corresponde deliberar o decidir al propio Congreso - este sería el caso en que, por ejemplo, si el Gobierno hace cuestión de confianza para que se elija a un determinado candidato en un puesto público para imponer a alguien como integrante de la Mesa Directiva del Congreso, o para que se apruebe un proyecto de ley sin que intermedie ninguna discusión o eventual modificación de sus términos-.

Como complemento de lo anterior, lo que sí puede ocurrir, en el marco de los principios constitucionales que delimitan nuestro sistema de gobierno, es que el Gobierno impulse al Congreso a ejercer sus competencias a través de una cuestión de confianza. Corresponderá en este caso al Congreso desempeñarlas en el marco de sus atribuciones constitucionales de este modo, el Gobierno puede hacer cuestión de confianza con la finalidad de obtener una ley del Congreso necesaria para desarrollar una determinada política pública, o incluso, con ese mismo propósito, buscar obtener una delegación de competencias legisferantes-.

En el marco planteado, y a partir de una evaluación integral del comportamiento del Congreso de la República peruano durante el 30 de septiembre de 2019, puede desprenderse entonces, con meridiana claridad, que en los hechos se produjo una denegatoria de la confianza que fue solicitada por el Gobierno. Efectivamente, hubo una serie de actos que muestran, sin margen de duda, que el Congreso estaba denegando la confianza solicitada con actos que, en el caso concreto, consisten en una votación expresa en contra de lo que fue pedido por el Presidente del Consejo de Ministros — que se discuta primero la propuesta legislativa para mejorar el procedimiento de elección-, así como otros comportamientos que mostraron la voluntad denegatoria del Congreso, como es el caso del impedimento para que el Presidente del Consejo de Ministros ingrese al hemiciclo, no darle carácter urgente a la propuesta que fue planteada, votar finalmente por los candidatos a magistrados, etc.

De este modo, y a mayor abundamiento, se aprecia que el Congreso de la República no respetó el tratamiento preferente que requería la propuesta planteada -artículo 105 de la Constitución-, atendiendo a que se trataba de una 
normativa de carácter procedimental, y por ende, de aplicación inmediata; y más bien programó su discusión para la tarde, desconociendo así el carácter urgente de lo propuesto. En similar sentido, y como ya fue indicado aquí, el Congreso rechazó la cuestión previa que había sido planteada para que se discuta la propuesta del Gobierno antes de continuar con el procedimiento de elección. De este modo, en suma, ha quedado totalmente de manifiesto que no se le dio ningún trato urgente o preferente a la propuesta sobre la cual se hizo cuestión de confianza y, en suma, que ésta fue rechazada.

Más aún, el Congreso peruano -o parte de él- ni siquiera permitió, pese a la habilitación expresa contenida en la Constitución -artículo 129 de la Constitución-, que el Presidente del Consejo de Ministros del Perú ingrese al hemiciclo y pueda, por propio derecho, hacer uso de la palabra. En este mismo sentido, se verifica que la regulación actualmente existente no prevé alguna restricción a la facultad constitucional $-y$ no acto de mera cortesía- del Presidente del Consejo de Ministros de participar en cualquier sesión y hacer uso de la palabra, ni por razones formales - no se requiere permiso o invitación previa - ni por razones materiales — no existe ninguna restricción sobre los temas o materias sobre los cuáles se puede intervenir-.

Todo lo antes descrito - la denegatoria de lo solicitado por el Presidente del Consejo de Ministros - hace irrelevante, entonces, la formalidad de que haya existido una votación aparentemente a favor de otorgar una confianza, pues, al tratarse de una herramienta de contrapeso político, es importante que esta no sea utilizada fraudulentamente, únicamente con la finalidad de evitar los efectos constitucionales que se desprenden del ejercicio de dicha institución. Lo contrario, según fue explicado, constituiría un fraude a la Constitución, proscrito expresamente en la Carta fundamental.
3. ¿El Ejecutivo estaba facultado para disolver el Congreso de acuerdo con lo estipulado en el artículo 134 de la Constitución?

Señalado lo anterior, y en la medida que el Gobierno podía plantear una cuestión de confianza en relación con el procedimiento de elección de magistrados, y a que la calificación jurídica de la denegatoria de confianza se ubica dentro de lo constitucionalmente posible, la disolución del Congreso de la República, contenida en el Decreto Supremo $N^{\circ} 165$ 2019-PCM, se encuentra dentro del supuesto previsto en el artículo 134 de la Constitución, el que faculta la disolución constitucional del Congreso peruano. ${ }^{16}$

Al respecto, es menester indicar que, en el marco de sus competencias constitucionales, en muchas ocasiones el Gobierno es un aplicador vinculante de la Constitución. Por ejemplo, cuando le corresponde interpretar, calificar jurídicamente o realizar actos conforme a las previsiones constitucionales que regulan sus atribuciones o competencias. De hecho, en general, cualquier operador del Derecho para aplicarlo necesita interpretar las disposiciones jurídicas, determinar los supuestos fácticos previstos en las normas, para posteriormente calificarlos jurídicamente, completando la operación de subsunción que, de manera simple, corresponde a la actividad jurídica. Esto mismo puede precisarse con respecto de la interpretación o calificación jurídica de la denegatoria de la confianza, que, dentro del marco de los criterios antes establecidos, y como última ratio en el marco del principio de solución democrática, le correspondió realizar al Gobierno. Cuando ello ocurre, y dentro los recaudos formulados, tal como ha ocurrido en el presente caso, el Gobierno estaría actuando dentro del marco de lo constitucionalmente posible. Por ende, no existe algún problema o incertidumbre en relación con la juridicidad de la medida.

16. "Artículo 134.-

El Presidente de la República está facultado para disolver el Congreso si éste ha censurado o negado su confianza a dos Consejos de Ministros.

(...)" 
Por lo expuesto, en suma, cabía la disolución del Congreso de la República del Perú, en la medida que se encuentra en el supuesto regulado en el artículo 134 de la Constitución: "[e]l Presidente de la República está facultado para disolver el Congreso si éste ha censurado o negado su confianza a dos Consejos de Ministros" no es lesivo de alguna competencia del Congreso de la República y se ha dado en el marco de nuestra forma de gobierno prevista en la Constitución. No existe, en nuestra opinión, el conflicto por menoscabo alegado en este caso.

Algunas expresiones finales: hay quienes han cuestionaron cómo se publicitó el acto de disolución presidencial. Para el suscrito, queda claro que el anuncio presidencial se perfecciona y materializa normativamente con la publicación del Decreto de disolución firmado por el ministro que lo firma. También queda claro que en ningún acápite de la Constitución se obliga contar con un refrendo de todo el Consejo de Ministros para avalar la validez y eficacia de este Decreto.

\section{CUANDO UNA CAUSAL DE VACANCIA ERRÓNEAMENTE INTERPRETADA SE CONVIERTE EN UNA MANERA RÁPIDA DE DESPRENDERSE DE UN/A PRESIDENTE/A INCÓMODO/A PARA UNA MAYORÍA PAR- LAMENTARIA: UNA HISTORIA RECIENTE QUE OJALÁ NO SE REPITA}

Cuando en cualquier manual de Derecho Constitucional se explica el significado del concepto "vacancia", se hace referencia a un mecanismo de control institucional $-\mathrm{y}$ no político, erróneamente sostiene el Reglamento del Congreso peruano-, el cual apela a una cuestión objetiva que permite comprobar que alguien no se encuentra en condiciones de ejercer un cargo. Por ello, la muerte, la renuncia o el abandono injustificado del puesto - por realizar un viaje sin autorización del Congreso, viajar a un lugar distinto al autorizado, o tomarse días fuera del Perú más allá de lo admitido- son causales de vacancia. Son hechos objetivos, fáciles de acreditar.

Aquello no exime a quien sea Presidente/a de tener responsabilidad en alguna de sus mani- festaciones. En ese sentido, el artículo 117 de la Constitución establece una lista de delitos que permiten su inmediato procesamiento y determinación de responsabilidad penal, sin necesidad de esperar al término de su mandato. Finalmente, el artículo 100 de la Carta de 1993, suerte de "juicio político a la peruana" permite pronunciarse en su momento por aquellas situaciones de mal desempeño presidencial.

Todo lo expuesto fue entendido así desde siempre, o por lo menos, desde hace muchos años. Y esta comprensión de las cosas incluía a lo señalado desde 1839 en todas nuestras constituciones - 1839, 1856, 1860, 1867, 1920, 1933, 1979, 1993-, y que ahora está regulado en el inciso 2 inciso 113 de la Carta vigente, la causal vigente "grave y permanente incapacidad física y moral".

Esto debe entenderse en el contexto que se plantea la causal. En esa época, la palabra "moral" no contenía una connotación ética. "Moral" venía del Derecho Privado francés del siglo XIX, y era el equivalente de mental. En pocas palabras, lo que se buscaba era apartar de la Presidencia de la República a alguien que físicamente no estaba en condiciones de desenvolverse por sí mismo -y no que padezca cualquier incapacidad, pues, como fácilmente puede comprender por la labor de Franklin D. Roosevelt como Presidente de la República en los Estados Unidos de América, a quien padecer de polio y movilizarse en silla de ruedas no le impidió su cargo-; o cuando el Presidente hubiese perdido la razón por cualquier enfermedad mental. Que conste que no hablo aquí de Presidenta, pues las mujeres lamentablemente recién tuvieron derecho al voto bien entrado el siglo XX.

Esta fórmula y su comprensión como "incapacidad mental" se siguió entendiendo de esta misma manera, como ya se comentó, en las Constituciones de 1856, 1860, 1867, 1920 y 1933. En el debate constituyente que llevó a la Constitución de 1979, alguien quiso discutir el tema, pero no obtuvo mayor respaldo. Moral era mental y nada más. Lo mismo ocurrió en el Congreso Constituyente que motivó a la conformación del texto de 1993, elaborado en un 
escenario en el cual más bien se buscaba fortalecer y no a exponer a la figura presidencial.

El problema se genera mucho después, con la salida del entonces Presidente de la República, Alberto Fujimori del país, supuestamente a un congreso en Brunéi, pero luego va a Japón y renuncia a la presidencia por fax. Esto ocasionó un gran malestar en el Congreso de la época, quien toma dos gestos políticos importantes: el primero, borrar la firma de Fujimori del texto de la Constitución de 1993 —esto realmente era un gesto, pues el efecto de la promulgación de una Constitución que cuente con varios años de vigencia ya está cumplido con creces. A una conclusión similar llegó la STC recaída en el Expediente $\mathrm{N}^{\circ}$ 00014-2002$\mathrm{PI}$, conocida como el caso "Colegio de Abogados de Cuzco"-; y luego, buscando dar un reproche ético a su comportamiento, no se le vaca por ausentarse del país sin autorización, sino por "una grave y permanente incapacidad moral".

Lo que fue previsto como la constatación de un hecho objetivo se convertía así en una pauta de evaluación de la conducta presidencial hecha a medida de la sola opinión de la comprensión de la composición congresal de turno. Se había abierto la caja de Pandora. Percibiendo el posible riesgo, y aprovechando que fuimos convocados a pertenecer a la "Comisión de Estudio de las Bases de la Constitución" conformada por el entonces Presidente Valentín Paniagua, señalamos que había que distinguir entre supuestos de mal desempeño y casos de enfermedad física o mental. Sin embargo, esa advertencia quedó en el olvido, en tanto y en cuanto los Presidentes posteriores a Paniagua - Toledo, García y Humala - contaban con mayoría parlamentaria, por votación propia o por sólidas alianzas con grupos que les permitían establecer esa mayoría parlamentaria.

La situación cambia cuando Keiko Fujimori gana la mayoría parlamentaria - su $38 \%$ de votos, con la aplicación del método D' Hondt, se convierte en el $51 \%$ de las curules-. Esta ventajosa situación se consolida luego de la evidente alianza entre el fujimorismo y el Par- tido Aprista Peruano, con pocos congresistas en número, pero con tres de ellos con mucha experiencia parlamentaria. Sin embargo, Pedro Pablo Kuczynski capitaliza el voto contrario al fujimorismo y al aprismo, y gana las elecciones presidenciales en segunda vuelta, solamente habiendo obtenido el $17 \%$ de la votación en la primera elección $-y$, por ende, su cobertura en el Congreso no pasaba del $20 \%$ de congresistas-. Pasamos entonces de un escenario de Presidente robusto a otro de Congreso robusto, el cual, por cierto, históricamente no ha dado buenos resultados en la historia peruana.

Cito algunos ejemplos al respecto. No corresponde aquí, como hacen algunos, el caso de La Mar: y es que allí, antes de estar ante un Congreso inusitadamente robusto dentro de un sistema presidencial, se cuenta con un gobierno de Asamblea de corte rousseauniano que entra en conflicto con el Presidente elegido por esa misma Asamblea. Muchos años después, Billinghurst pierde el enfrentamiento entre el Presidente y al Congreso de aquel entonces, y se da un golpe de Estado militar encabezado por Óscar R. Benavides.

Algo similar sucede con Bustamante y Rivero, quien llega al gobierno con el apoyo de su entorno, acompañado por militantes del Partido Aprista Peruano. Pronto surgen desavenencias entre apristas y bustamantistas. En ese contexto, se rompe la alianza entre las dos fuerzas políticas. Es más, se da una rebelión de un grupo de militantes apristas, y el presidente Bustamante y Rivero señala que "EI APRA se ha puesto al margen de la ley". Pocos días después, no es el Congreso quien destituyó a Bustamante y Rivero, sino un golpe de Estado encabezado por el General Manuel A. Odría.

No fue muy distinto el cuadro vivido durante el primer gobierno del arquitecto Fernando Belaunde Terry. Si bien su partido político logró una alianza con la Democracia Cristiana, la alianza de los acérrimos enemigos de antemano: el Partido Aprista y el Partido Unión Nacional Odriísta tenían mayoría en el Congreso e hicieron un uso excesivo de interpelaciones y censuras a los ministros y ministras del Gobierno que

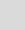


desestabilizó políticamente al país. Cuando el Partido Aprista quiso revertir la caótica situación existente y coordina con Acción Popular configurar una alianza y apoyar con un nuevo Gabinete -el Gabinete Hercelles o el "Gabinete conversado"-, viene de inmediato el golpe militar del general Juan Velasco Alvarado.

Fujimori, en su primer gobierno, no tenía mayoría parlamentaria, pero el Congreso de aquel entonces no hizo intento alguno de destituirlo. Fujimori más bien cuestionó ácidamente al Congreso que no controlaba, así como al quehacer de otras entidades. Aquí no es el Congreso quien actúa contra el Presidente, sino todo lo contrario: fue el entonces Presidente Fujimori quien asumió plenos poderes el año 1992 y sin seguir los parámetros constitucionales, disolvió el Congreso e interviene una serie de otras entidades estatales.

Luego de la caída de Fujimori, la distorsión de la comprensión de un hecho objetivo y de clara determinación - una causal de vacancia- en un instrumento para evaluar y determinar un mecanismo de salida de quien preside la República que podríamos denominar "exprés" sin recurrir a una subcomisión de Acusaciones Constitucionales y a la Comisión Permanente antes de ir al Pleno-.

Como ya es de conocimiento general, esto es lo que la mayoría aprofujimorista intentó con el ex Presidente Kuczynski. Y casi lo consiguen, pues la moción de censura pasó holgadamente las dos primeras etapas previstas por la normatividad vigente, pero no consiguió el apoyo de dos tercios de los congresistas en el Pleno. Luego se descubrió el desarrollo de una estrategia para evitar que se alcancen los votos que pasaba, entre otras acciones, por el indulto a Alberto Fujimori. El descubrimiento sobre cómo se llegó a esas acciones, unido al descubrimiento de que empresas pertenecientes al entonces Presidente de la República habían recibido dinero de Odebrecht ${ }^{17}$, hicieron insostenible su situación.

Antes de que pueda prosperar un segundo pedido de vacancia por grave y permanente incapacidad moral, Pedro Pablo Kuczynski, desacreditado incluso en muchos sectores que apoyaron su decisión, se ve obligado a renunciar a su ya insostenible condición de Presidente de la República. No se vacó al entonces Presidente con un uso distorsionado de una causal de vacancia, pero se estuvo muy cerca de hacerlo.

Luego vino la asunción de Martín Vizcarra y su abierto enfrentamiento con el Congreso con mayoría aprofujimorista, que concluyó con el cierre del Congreso ya explicado en este texto, y un pronunciamiento del Tribunal Constitucional, se coincida o no con la sentencia emitida, donde el Tribunal afirma sus roles de pacificación, integración y ordenación.

Esta misma actuación de pacificación, integración y ordenación del Tribunal Constitucional peruano es lo que busca el gobierno de turno cuando desde el Congreso busca plantearse una moción de vacancia por grave y permanente incapacidad moral. El Gobierno de aquel entonces plantea un proceso competencial por menoscabo, pues asume que el Congreso, al recurrir a la interpretación de la causal de vacancia "grave y permanente incapacidad moral" que viene utilizando, y a la cual el Gobierno considera una interpretación inconstitucional, el Congreso le está recortando al Gobierno su función principal, la de poder desarrollar su plan de Gobierno.

El caso que justificaba el planteamiento del proceso competencial era el denominado caso "Richard Swing", vinculado a contrataciones poco claras hechas reparticiones a quien

17. Nota del editor: la constructora brasileña Odebrecht se vio envuelta a principios del 2015 en el caso "Lavajato", donde una investigación federal brasileña descubrió una compleja red de sobornos a lo largo del continente, particularmente en el Perú involucrando a una serie de altos funcionarios _-incluyendo a los ex Presidentes de la República Toledo, Humala, García y Kuczynski-. 
usaba el nombre artístico de "Richard Swing". ${ }^{18}$ Unos audios parecían acreditar la intención de desvirtuar cualquier tipo de relación entre el entonces Presidente Vizcarra y "Richard Swing". Eso es lo que asume el Congreso como "grave y permanente incapacidad moral", pero no consigue los votos suficientes para vacarlo. Ahora bien, con ello no terminaba el proceso, pues la denominada dimensión objetiva de un proceso competencial obliga a resolver y pronunciarse sobre el aspecto controvertido. Por ello, se considera un proceso de impulso público.

Sin embargo, y muy a despecho de estas consideraciones, que llevaban al Tribunal Constitucional a tener que pronunciarse sobre como debía entenderse la causal de vacancia "grave y permanente incapacidad moral" e incluso evaluar cómo se había utilizado esta causal, con todo respeto a su posición, pero discrepando abiertamente con ella, cuatro de los siete magistrados del Tribunal eludieron cumplir con su papel pacificador, integrador y ordenador, $y$ optaron por una comprensión formalista de las cosas -el caso fue planteado al caso "Swing", causa que concluyó sin que proceda la vacancia de Vizcarra, el cual finalmente es vacado por otro tema: acusaciones de soborno durante su gestión como Gobernador Regional de Moquegua, acusaciones hechas por un aspirante a colaborador eficaz. Entonces, ya no tenían causa qué resolver, y por ello debía declararse improcedente la demanda por sustracción de materia-.

La respuesta formalista otorgada al caso deja entonces abierta la posibilidad de recurrir a este uso distorsionado de una causal de vacancia para, con la fuerza de votos sin sustento, carentes de motivación, una mayoría parlamentaria despoje de su cargo al Presidente o Presidenta de la República sin seguir los parámetros cons- titucionales. Esta situación se agrava en el último año de la gestión presidencial, pues en esa época quien preside no se encuentra habilitado a disolver constitucionalmente al Congreso, pero el Congreso sí se siente "autohabilitado" para insistir en vacar al Presidente/a. Este es un ejemplo sobre cómo puede generarse una situación de pérdida de balance de poderes que pone en riesgo la misma continuidad del orden democrático, y lo peligroso que puede resultar que un Tribunal no defina situaciones - no haga su trabajo de "concretización" - que tienen respuesta dentro de lo constitucionalmente posible $y$, sobre todo, sea parte de lo constitucionalmente obligatorio. A estas materias dedicaremos nuestro interés de inmediato.

\section{A MODO DE CONCLUSIÓN: LAS TAREAS Y FUNCIONES DE UN TRIBUNAL CONSTITU- CIONAL Y SUS ALCANCES ANTE LA EXIS- TENCIA DE LO CONSTITUCIONALMENTE POSIBLE Y LO CONSTITUCIONALMENTE OBLIGATORIO}

Lo primero que hay que señalar es que actualmente nos encontramos en un escenario de constitucionalización y convencionalización, en los que se enmarca la comprensión contemporánea del rol de los jueces y juezas constitucionales. Esta comprensión es imprescindible para poder reconocer las potencialidades, pero también los límites de los tribunales constitucionales en casos como el presente.

En efecto, la labor de un juez o jueza constitucional consiste en la de interpretación del Derecho de acuerdo con parámetros constitucionales, y más propiamente de una "Constitución convencionalizada". En este orden de ideas, le corresponde realizar labores de "constitucionalización del Derecho", ya sea en sus efectos directos - "constitucionalización judicialización", referida a la relación entre y con las diferentes 
instituciones estatales; "constitucionalización elevación", relacionada con el sistema de fuentes o la producción de normas dentro de un Estado; y "constitucionalización transformación", vinculada a las diversas disciplinas jurídicas y sus distintas instituciones-, o también a sus efectos indirectos - modernización del Derecho, unificación del orden jurídico, simplificación del ordenamiento-.

Junto a ello, compete al juez/a constitucional, asimismo, desarrollar una labor de "constitucionalización de la política", pues el quehacer político - así como el social o el económicono puede manejarse al margen de lo dispuesto en los diferentes preceptos constitucionales y lo que se infiere de ellos. Aquello, ciertamente, permite dejar de lado el mantenimiento de figuras arcaicas - previas al proceso de constitucionalización- como es el caso de las political questions, "actos políticos o de gobierno" y lo que ellas involucran: la subsistencia de decisiones que buscaban sustraerse de ser revisadas bajo parámetros jurídicos en sede jurisdiccional. Esto, bien entendido, habilita incluso a que jueces y juezas constitucionales no solamente controlen, sino que hasta se permitan hacer sugerencias y tener iniciativas frente a la configuración de políticas públicas, para así asegurar la constitucionalidad de las mismas.

Esta referida "constitucionalización de la política" permite entender que, en tanto y en cuanto la legitimación del poder en un Estado Constitucional es jurídica, y ello básicamente se tutela en sede jurisdiccional, al mismo tiempo, se le reclama a jueces y juezas constitucionales que asuman labores de integración social, las cuales, siquiera enunciativamente, aluden a apuntalar elementos de cohesión social — búsqueda de que toda persona pertenezca a una comunidad donde pueda realizar sus proyectos de vida-, inclusión social - esfuerzo para incorporar a quienes se encuentran excluidos del sistema político, de la configuración de lo económico o de la capacidad de ejercer sus derechos o su cultura a cabalidad-, reconciliación social - apuntalamiento de una superación colectiva de períodos asumidos como difíciles dentro de la historia de nuestros países-o prevención social - intento de consolidación de un clima con ausencia de conflictos, o con una solución rápida y eficaz de los ya existentes-.

Sin embargo, esto no es lo único a tomar en cuenta si se habla sobre cuáles debieran ser los actuales parámetros de la actuación de un/a juez/a constitucional. Ya habíamos dicho que ello partía de comprender su quehacer desde el parámetro de una Constitución "convencionalizada" o, dicho con otras palabras, dentro de una lógica de "convencionalización del Derecho". En todo caso, corresponde concebir la labor de estos/as juzgadores/as - y no solamente las de ellos, sino también la del conjunto de las entidades estatales, en el marco de sus competencias-, en una dinámica de verdadero diálogo, destinado a la construcción de un Derecho común, cuyo sustento es el de la comprensión de los derechos conforme a los tratados sobre Derechos Humanos suscritos por cada Estado o a las pautas sobre derechos que hoy se nos presentan como normas de ius cogens.

Lo anterior, por cierto, viene de cara con ciertas funciones que son propias de dicho Tribunal. Estos roles o funciones son los de mediación, entendiendo que las cortes constitucionales cumplen con una función moderadora, reguladora y preservadora de la unidad política nacional, buscando la armonía social, no obstante las diferencias propias de sociedades cada vez más plurales y complejas; los de integración social, que aluden a la búsqueda de cohesión social, de inclusión y reconocimiento, de reconciliación y de prevención social — clima de ausencia de conflictos-; y los de orientación, referidos a la tarea de afirmar los valores constitucionales y de consolidar una identidad ciudadana sobre la base de lo recogido en la Constitución.

Es dentro de ese escenario que a todo Tribunal Constitucional, a toda alta Corte que hace sus veces, y a todo juez/a constitucional, toca desempeñar una labor de concretización de la Constitución. Dicho con otras palabras, una tarea de desarrollo de los principios, valores, derechos, deberes y demás prescripciones que contiene una Constitución, las cuales no se circunscriben a su lectura estrictamente literal. 
Como bien señalaba García de Enterría, toda Constitución contemporánea propia de un Estado constitucional es en rigor un conjunto normativo. Aquello reclama su interpretación sistemática con todo el mismo texto constitucional, con los parámetros convencionales vigentes - tratados, jurisprudencia y normas de ius cogens, por lo menos-, y lo que objetivamente se puede deducir como implícito a ello.

La concretización de la Constitución, como bien señalaba Hesse, y quienes han seguido esa línea de pensamiento, no puede entonces ser comprendida de una manera estática y cerrada. Una Constitución no es hoy una camisa de fuerza, sino un punto de partida para generar o recrear respuestas - según fuera el caso-a problemas que se presentan en la realidad misma de un Estado Constitucional -o por lo menos, que apunte a hacerlo-. En muchos casos, como ya lo ha dicho el mismo Tribunal Constitucional peruano en casos como "Lizana Puelles" -STC recaída en el Expediente $\mathrm{N}^{\circ}$ 058542005-AA-, recurrir a una interpretación literal de la Constitución sería realmente lo inconstitucional, o lo ajeno a lo constitucionalmente conforme - necesario o posible-.

Esta última definición nos lleva también a una comprensión bastante más amplia de lo "constitucional" que lo asumido a nivel interpretativo o lo hecho suyo por parámetros interpretativos más propios de un contexto decimonónico. Es cierto que no todo es constitucional. Es cierto también que hay aspectos que son claramente constitucionales, con un reconocimiento a nivel de las Constituciones, unidas al plano convencional y a lo asumido como ius cogens, como ya fue explicado. Pero no se puede negar también que, al ser la Constitución un punto de partida para una interpretación dinámica frene a los graves y variables problemas de una sociedad, las disposiciones constitucionales, que son de diversa naturaleza - algunas principales, otras con vocación de reglas, otras y un largo etcétera-, permiten más de una comprensión de lo que se puede o debe hacer.

Aquí entramos entonces al mundo de lo "constitucionalmente posible", donde los diferentes operadores jurídicos -y sobre todo, los vinculantes-, tienen un margen de acción con cierta discrecionalidad, más no arbitrariedad. Las diferentes disposiciones de una Constitución, como bien ha dicho entre otros Guastini, cuentan con diversos sentidos o comprensiones normativas. Aquello otorga un amplio, más no ilimitado e incontrolable margen de acción a los intérpretes vinculantes de la Constitución, así como a los poderes públicos e incluso a los particulares, pero siempre de ciertos parámetros, pues, caso contrario, la discrecionalidad se convierte en arbitrariedad, y por ende, en la negación de lo que corresponde a un Estado Constitucional.

Lo que se acaba de señalar tiene enorme importancia dentro de la interpretación constitucional contemporánea. Miles son los ejemplos que podrían ponerse al respecto, pero aquí solamente mencionaremos uno: en principio es la interpretación hecha dentro de lo constitucionalmente posible la que ha permitido en el Perú comprender como ámbito de acción del "amparo contra resoluciones judiciales" no solamente al derecho a la tutela procesal efectiva - dentro de la cual se ha comprendido a la tutela judicial efectiva y debido proceso-, tal como lo haría una lectura literal del artículo 4 del Código Procesal Constitucional. Hoy cabe la interposición de amparos contra resoluciones judiciales incluso buscando evitar la violación o amenaza de violación de los denominados "derechos implícitos".

Si esto es constitucionalmente posible, hay que estar atentos a lo que los jueces y juezas constitucionales pueden o no hacer para resolver los problemas de configuración y los conflictos que pueden surgir en la conformación y consolidación de un sistema de gobierno. 